\title{
CARACTERIZAÇÃO HIDROGEOQUÍMICA DOS AQUÍFEROS DA REGIÃO DA APA CARSTE DE LAGOA SANTA, MG
}

\author{
HYDROGEOCHEMICAL CHARACTERIZATION OF AQUIFERS IN THE REGION OF EPA \\ LAGOA SANTA KARST, MG
}

\author{
Luisa Costa Martins VIEIRA ${ }^{\mathbf{1}}$, Leila Nunes Menegasse VELÁSQUEZ ${ }^{2}$, Tânia Mara \\ DUSSIN ${ }^{2}$, Ricardo Perobelli BORBA ${ }^{3}$ \\ ${ }^{1}$ Programa de Pós-Graduação em Geologia, Instituto de Geociências, Universidade Federal de Minas Gerais. E-mail: \\ luisacmvieira@gmail.com \\ ${ }^{2}$ Departamento de Geologia, Instituto de Geociências, Universidade Federal de Minas Gerais. E-mails: menegase@yahoo.com.br; \\ tdussin@gmail.com \\ ${ }^{3}$ Instituto de Geociências da Universidade Estadual de Campinas. E-mail: borba@ige.unicamp.br

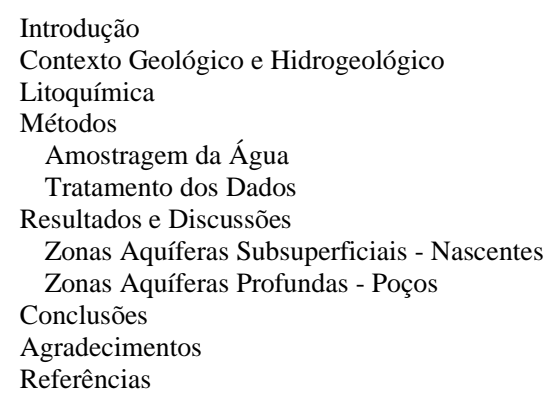

RESUMO - Estudo hidrogeoquímico foi realizado envolvendo a região da Área de Proteção Ambiental Carste de Lagoa Santa, 504km², a norte do município de Belo Horizonte. As litologias aquíferas envolvidas foram a sequência pelito-carbonática da Formação Sete Lagoas, metapelitos da Formação Serra de Santa Helena e granito-gnaisses do Complexo Belo Horizonte. A primeira divide-se em Membro Pedro Leopoldo, inferior, encerrando calcários impuros, com intercalações pelíticas, e Membro Lagoa Santa, superior, contendo calcários puros. As águas são bicarbonatadas cálcicas, secundariamente bicarbonatadas mistas a sódicas, quando associadas ao embasamento e coberturas. As concentrações de $\mathrm{Ca}^{2+}$ e $\mathrm{Si}^{4+}$ foram fundamentais para a distinção entre as unidades aquíferas carbonáticas e não carbonáticas, permitindo também identificar águas mistas, elucidar sobre o meio de recarga e compartimentar horizontal e verticalmente o sistema aquífero. A heterogeneidade litológica conferida ao membro inferior levou a sua subdivisão em 4 tipos hídricos, enquanto as águas do Membro Lagoa Santa são homogêneas, refletindo a sua homogeneidade litológica. A alta produtividade dos poços profundos deve-se à dissolução de porções rochosas mais puras e à localização próxima a falhamentos e de contato litológico entre os membros, enquanto nas nascentes é controlada pela intensidade dos processos de carstificação dos calcários mais puros do Membro Lagoa Santa.

Palavras-chave: APA Carste de Lagoa Santa. Hidrogeoquímica. Aquíferos cársticos.

ABSTRACT - This hydrogeochemical study involves the Environmental Protection Area of Lagoa Santa Karst, 504km², north of Belo Horizonte. The aquifer lithologies concerned were the pelito-carbonate sequence of Sete Lagoas Formation, metapelites of Serra de Santa Helena Formation and granite-gneisses of Belo Horizonte Complex. The first one divides into Pedro Leopoldo Member, lower, composed by impure limestones, with pelitic intercalations, and Lagoa Santa Member, upper, containing pure limestones. The waters are calcium bicarbonated, secondarily mixed to sodium bicarbonated, when associated to basement and coverings. The concentrations of $\mathrm{Ca}^{2+}$ and $\mathrm{Si}^{4+}$ were fundamental for distinction between carbonate and noncarbonate aquifer units, also allowing the identification of mixed waters, elucidation of the recharge mean and horizontal and vertical compartmentalization of aquifer system. The lithological heterogeneity conferred on the lower Member led to its subdivision into four water types, while the waters of the Lagoa Santa Member are homogeneous, reflecting its lithological homogeneity. The high productivity of the deep wells is due to the dissolution of purest rock portions and to this location near faults and of lithological contact between the members, whereas in springs the intensity of karstification processes in purer limestones of Lagoa Santa Member controls the flow rate.

Keywords: EPA Lagoa Santa Karst. Hydrogeochemistry. Karst aquifers.

\section{INTRODUÇÃO}

Visando a identificação e quantificação das propriedades e constituintes químicos das águas subterrâneas, o foco principal dos estudos hidrogeoquímicos consiste na assimilação da origem e da evolução química dos componentes presentes na água, decorrentes de processos físico-químicos e biogeoquímicos ao longo do percurso do fluxo (Santos, 2008; Mestrinho, 2008). Uma vez que a composição da água subterrânea é, geralmente, influenciada pelo solo ou rocha em que percola, a compreensão destes processos em conjunto com as características 
hidrogeológicas permite melhor apreciação da interação água-rocha e da qualidade da água para determinado uso (Mestrinho, 2008). Em ambientes cársticos predominantemente formados por rochas carbonáticas, a hidroquímica do aquífero está sujeita à circulação e atividade da água, que dependem fortemente de fatores geológicos, geográficos e climáticos e que ditam, ainda, a intensidade da carstificação e o desenvolvimento das drenagens subterrâneas (Silva, 2008).
Localizada a $30 \mathrm{~km}$ a norte de Belo Horizonte, a área estudada possui 509,4 $\mathrm{km}^{2}$ integrando totalmente a Área de Proteção Ambiental (APA) Carste de Lagoa Santa acrescida de $100 \mathrm{~km}^{2}$ a norte e a oeste. Abrange os municípios de Confins, Vespasiano, Lagoa Santa, Pedro Leopoldo, Matozinhos, Prudente de Morais e Funilândia. Sua delimitação é feita a partir de drenagens principais, Rio das Velhas a leste e Ribeirão da Mata a oeste e sul, e secundárias a norte (Figura 1).

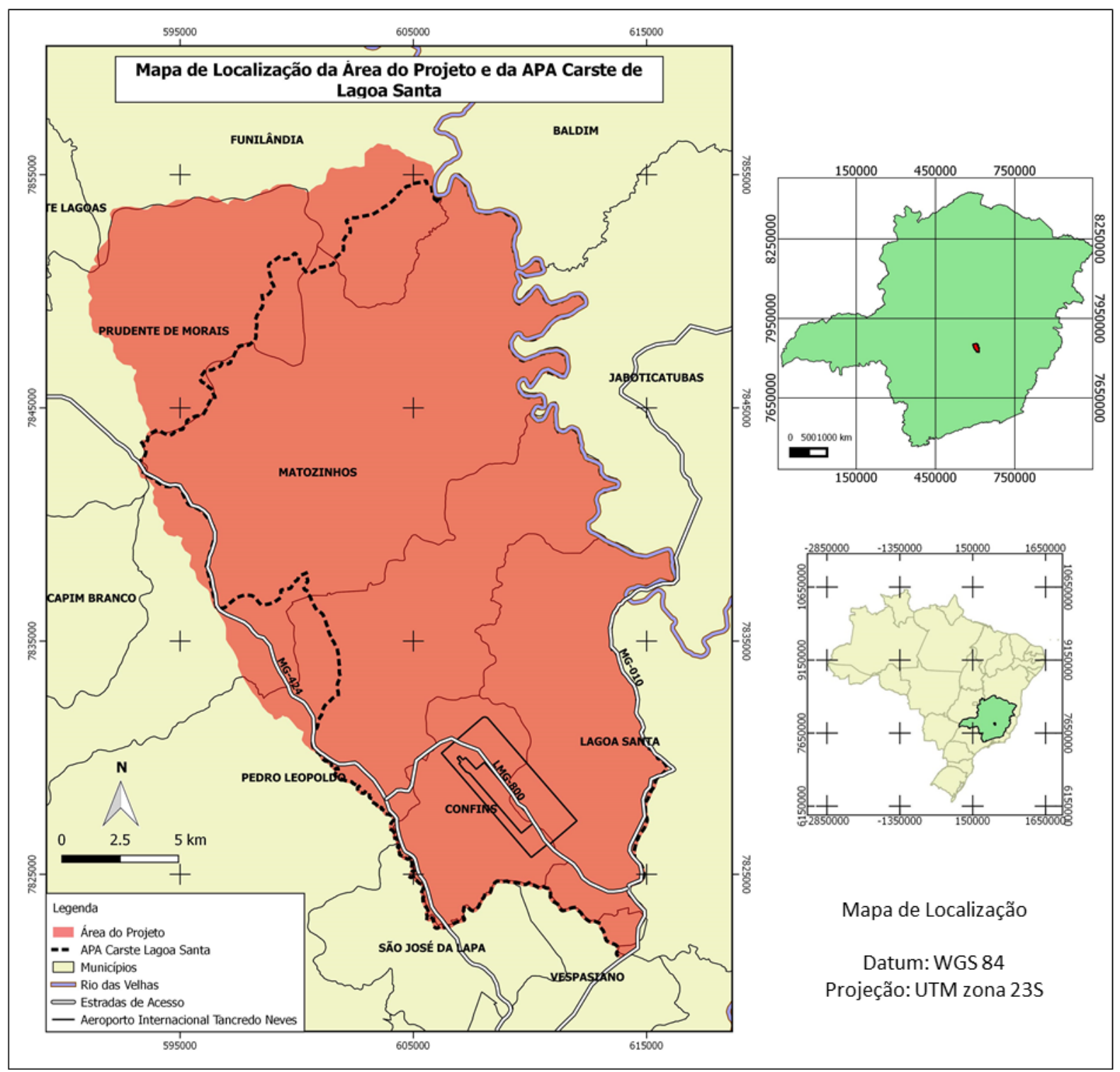

Figura 1 - Mapa de localização da área do projeto e da APA Carste de Lagoa Santa (Vieira, 2018).

Nesta região se desenvolve uma geomorfologia cárstica típica composta por condutos, cavernas, dolinas, surgências e sumidouros, sobretudo nas rochas carbonáticas da Formação Sete Lagoas, que resulta em uma complexa rede de fluxo de água subterrânea. Juntamente às características naturais sobrepõese as diversas e intensas atividades econômicas como mineração, agricultura e pecuária, além de intenso crescimento urbano, cujas consequências elevam o risco de contaminação e de superexplotação dos aquíferos, numa área já naturalmente frágil.

Nesse trabalho, o estudo hidrogeoquímico foi realizado visando a se investigar a compartimentação hidrogeoquímica vertical e horizontal das águas subterrâneas em função da litoquímica, do comportamento hidrodinâmico dos aquíferos 
e das entradas d’água, tanto das zonas aquíferas subsuperficiais quanto profundas.

Para tanto, o levantamento hidrogeológico partiu de uma análise da qualidade da água que abrange toda região da APA Carste de Lagoa Santa (CPRM/IBAMA, 1998). Tais estudos tiveram maior foco nas características hidráulicas e potencialidades dos aquíferos do que na hidrogeoquímica propriamente dita. A caracterização hidroquímica realizada no projeto de zoneamento ambiental (CPRM/IBAMA, 1998) não objetivou ainda a uma diferenciação hidrogeoquímica pormenorizada, segundo todas as unidades estratigráficas mapeadas.

Outros importantes trabalhos foram executados na região, contudo em regiões específicas e objetivos afora um estudo hidrogeoquímico propriamente dito. Auler (1994) determinou alguns fluxos de água subterrânea na APA Carste de Lagoa Santa, nos municípios de Pedro Leopoldo e Matozinhos, de direções NW-SE, EW e SW-NE a partir de dados hidroquímicos e da aplicação de traçadores corantes. Silva (2003) e Pessoa (2005) realizaram a caracterização e modelagem hidrogeológica na região próxima ao município de Lagoa Santa, com introdução de uma caracterização hidrogeoquímica no último trabalho. Um modelo hidrogeológico preliminar com intuito de detalhar a hidrogeologia e a hidrodinâmica dos aquíferos da região de Sete Lagoas também foi proposto por Batista (2009) e refinado, posteriormente, por Machado (2011) acrescentando uma avaliação de vulnerabilidade dos mesmos. Carneiro (2013) complementa estes estudos com a modelagem hidrogeoquímica visando conhecer os processos naturais ocasionados pela interação água-rocha.

Assim sendo, a lacuna de trabalhos específicos em hidrogeoquímica na área, aliada à intensificação das atividades antrópicas e à alta vulnerabilidade natural dos aquíferos, julga-se relevante a caracterização hidrogeoquímica com finalidade em si, isto é, a compartimentação química das águas naturais através da interação água-rocha e dos fatores determinantes dos processos geoquímicos, bem como ferramenta para o entendimento da hidrodinâmica aquífera e do aprimoramento do modelo físico do sistema aquífero. Dentre estes processos hidrogeoquímicos, destaca-se a dissolução dos carbonatos, que promove maior ou menor intensidade de porosidade secundária e, consequentemente, diferentes graus de produtividade do aquífero. $\mathrm{O}$ conjunto de todas essas informações permitem a consolidação de uma rede de monitoramento qualitativa (e quantitativa), que represente mais precisa e adequadamente os diferentes tipos hidroquímicos identificados.

Este trabalho apresenta os resultados do estudo da caracterização hidrogeoquímica das águas subterrâneas dos aquíferos cársticos a partir da litoquímica, análise de águas de nascentes e poços profundos, que apoiarão a concepção de um modelo físico hidrodinâmico e a implantação de uma rede de monitoramento qualitativo e quantitativo na região por parte dos órgãos competentes.

\section{CONTEXTO GEOLÓGICO E HIDROGEOLÓGICO}

$\mathrm{Na}$ área de estudo ocorre o embasamento cristalino, constituído pelo Complexo Gnáissicomigmatítico Belo Horizonte, de composição granodiorítica, sobreposto pelas sequências metassedimentares neoproterozoicas pelito-carbonáticas do Grupo Bambuí, Supergrupo São Francisco (Almeida, 1977; Dardenne, 1978; Alkmim \& Martins-Neto, 2001; Alkmim, 2004), composto pelas formações Sete Lagoas e Serra de Santa Helena (Figura 2).

O embasamento é restrito a uma estreita faixa na porção sudoeste, constituído por granodioritos de granulação média a grossa, biotita e anfibólio orientados. Compõem os aquíferos fissurais de menor expressão na área, associados a fraturas pouco abertas (CPRM/IBAMA, 1998).

Sobrepostas ao embasamento ocorrem os dois membros da Formação Sete Lagoas de maior extensão territorial: Membro Pedro Leopoldo, inferior e Membro Lagoa Santa, superior (CPRM, 2010). Juntas estas unidades constituem o principal aquífero da região, ainda que a superior apresente maior produtividade média $(14,42$ $\left.\mathrm{m}^{3 / \mathrm{h}} / \mathrm{m}\right)$ que a unidade inferior $\left(2,78 \mathrm{~m}^{3} / \mathrm{h} / \mathrm{m}\right)$ (CPRM/IBAMA, 1998).

O Membro Pedro Leopoldo aflora nas bordas oeste, sul e leste da área, e é composto por metacalcários de granulação muito fina a microcristalina, impuros formados principalmente por calcita, sericita, quartzo e, de forma subordinada, sulfetos disseminados. Suas rochas apresentam estruturas mais pronunciadas decorrentes da intercalação pelítica, como foliação, lineação de estiramento, clivagens de crenulação, dentre outras (Vieira et al., 2018). Esse membro possui espessura média aproximada de 150m (CPRM, 1994). 


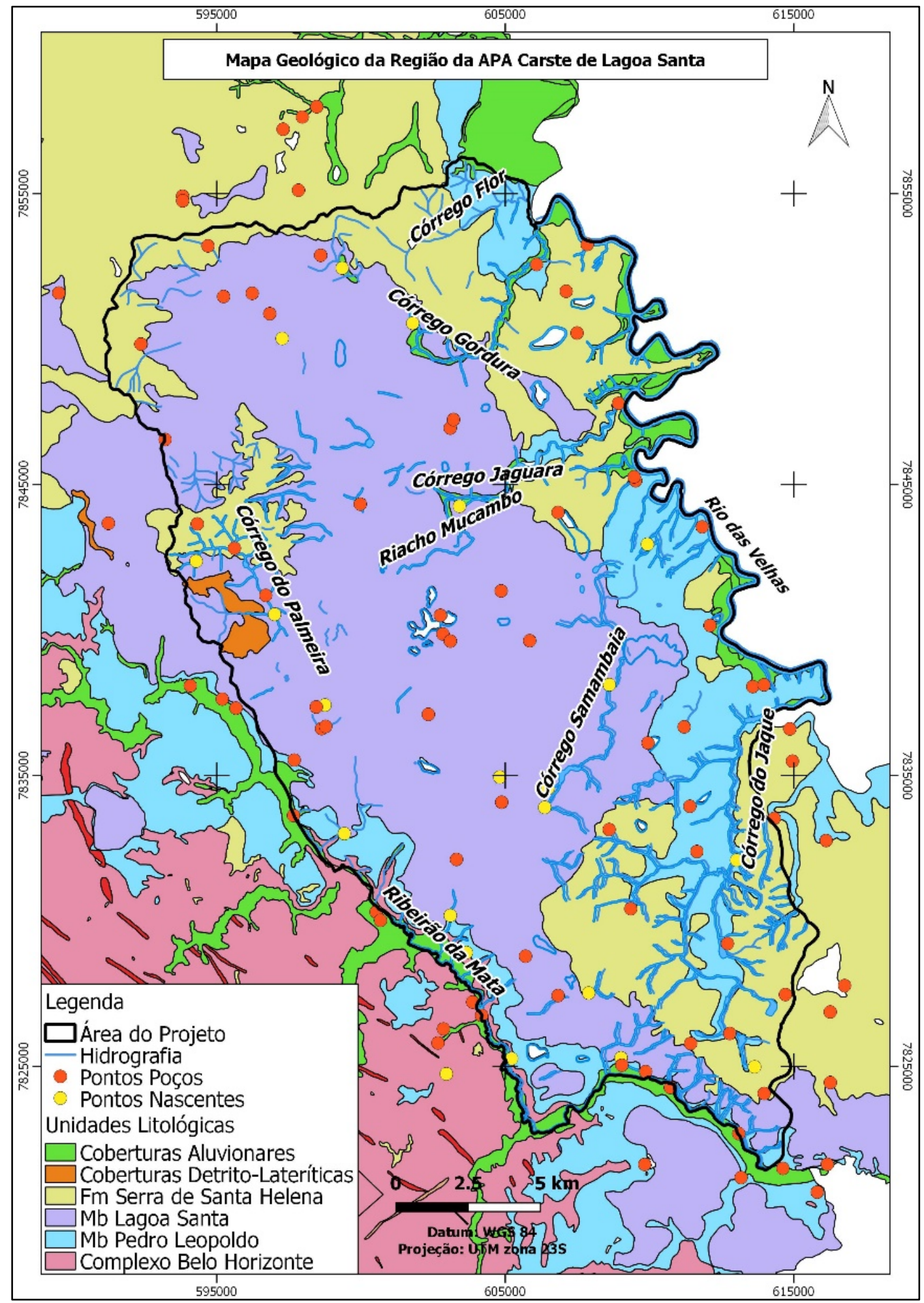

Figura 2 - Mapa geológico da área do projeto com pontos de nascentes e poços tubulares amostrados para análise química. Base geológica 1:100.000 modificada de CPRM - Serviço Geológico do Brasil das folhas Belo Horizonte, Contagem, Sete Lagoas e Baldim. Disponível em geobank do site da empresa: http://www.cprm.gov.br/.

O Membro Lagoa Santa ocupa a porção central da área e é composto por metacalcários calcíticos com sulfetos disseminados, granulação fina a média e cor cinza escuro (CPRM, 2010). A foliação se deve ao estiramento dos cristais de calcita em direção preferencial, normalmente subparalela ao acamamento, sendo comuns veios de calcita, milonitização e dobras isoclinais intrafoliais (Vieira et al., 2018). A espessura média desse membro é de cerca de 100m (CPRM, 1994).

A extensa distribuição destas rochas carbonáticas que formam o aquífero cárstico da região promove uma rede de drenagem predominantemente subterrânea, caracterizada pela grande variedade de condutos e cavernas, frequentemente interligados com feições epicársticas, como 
dolinas, uvalas, sumidouros e surgências, com baixa densidade de escoamento superficial (CPRM/IBAMA, 1998). Em virtude dessa intensa carstificação, os rios normalmente têm suas nascentes nos terrenos carbonáticos e são drenados posteriormente para condutos subterrâneos, bem como grande parte das águas pluviais (Ribeiro et al., 2016).

Hidrograficamente, a área de estudo se insere na sub-bacia do Rio das Velhas e possui o rio homônimo como principal curso d’água e nível de base local. O Ribeirão da Mata, que bordeja a APA Carste de Lagoa Santa no limite sul, é seu principal afluente na região (Meneses, 2003). Dentro dos limites da área drenam seis córregos que constituem as seis principais sub-bacias locais: Jaque, Samambaia, Jaguara, Palmeira, Gordura e Flor (Figura 2).

A Fm. Serra de Santa Helena está sobreposta à Fm. Sete Lagoas, por vezes sobre o Membro Pedro Leopoldo outras sobre o Lagoa Santa. Ocorre principalmente nas porções norte, nordeste e sudeste da área, e é constituída por metassiltitos formados principalmente por quartzo e sericita e, secundariamente, por argila e óxidos de ferro. Apresentam-se intensamente intemperizados e exibem uma forte laminação em consequência da intercalação da sericita e do quartzo. As rochas desta unidade formam aquíferos de expressividade moderada a baixa (CPRM/IBAMA, 1998).

As coberturas cenozoicas são representadas por sedimentos detrito-lateríticos, uma ocorrência restrita a oeste de solo laterítico, de espessuras maiores que 2 metros, e depósitos aluvionares acompanhando os cursos d'água, de espessuras que variam de centímetros a 3 metros (CPRM/IBAMA, 1998).

O manto de alteração, por sua vez, possui espessuras bastante variáveis a depender da morfologia do relevo em que se encontra, abrangendo valores de poucos centímetros a dezenas de metros, podendo chegar a mais de $100 \mathrm{~m}$ de espessura nos topos de alguns platôs (Pessoa, 2005).

Os contatos entre todas as unidades litológicas ocorrem majoritariamente por falhas de descolamento, podendo também ser gradacional entre os Membros Pedro Leopoldo e Lagoa Santa (CPRM, 2003). Os cristais de carbonatos de ambos os membros se apresentam recristalizados em decorrência aos eventos deformacionais que acometeram a região, o que resultou na obliteração de grande parte das estruturas primárias (CPRM, 2010).

Ao correlacionar a geologia estrutural e os fluxos de água na área, Ribeiro et al. (2019) ressaltam a importância das fraturas E-W de alto ângulo (maior ou igual a $45^{\circ}$ ) dos calcários para a condução de água no sistema cárstico, no sentido preferencial de oeste para leste, em direção ao nível de base regional. CPRM/IBAMA (1998) observaram predomínio de fraturas e condutos de direções NE-SW e NW-SE para os aquíferos Sete Lagoas e Santa Helena.

Ribeiro et al. (2019) também citam estas direções de fraturas e condutos, além da direção EW, em concordância com direção de fluxo de traçadores, como principais indícios de que o acamamento e as fraturas E-W de alto ângulo são as estruturas que norteiam o fluxo regional.

\section{LITOQUÍMICA}

Devido a sua maior relevância aquífera da região, o foco da litoquímica se deu na análise dos metacalcários da Formação Sete Lagoas, principalmente na separação química dos dois membros que compõem a unidade. Os dados da análise química usados foram de Vieira et al. (2018) e os resultados da difração de raio-X (DRX) encontram-se na tabela 1.

As rochas do Membro Lagoa Santa são classificadas como calcários mais ou menos magnesianos, segundo diagrama ternário de Miche et al. (2013) para rochas carbonáticas recristalizadas (Figura 3). A classificação remete à sua composição essencialmente calcítica $(\mathrm{CaO}=54,4-56,8 \%)$, com baixos teores de $\mathrm{SiO}_{2}$ $(0,1-1,9 \%)$ e $\mathrm{MgO}(0,1-0,4 \%)$, obtida via DRX. As rochas do Membro Pedro Leopoldo são subdivididas em calcários dolomíticos silicosos (predominantes), calcários mais ou menos magnesianos, calcários silicosos mais ou menos magnesianos e cherts calcários-silicosos, segundo classificação de Miche et al. (2013). Estas rochas apresentam grande variabilidade faciológica, de fácies mais puras àquelas de maior teor de intercalações pelíticas e de dolomita, indicada pela abrangência do conteúdo de $\mathrm{CaO}(20,6-55,2 \%), \mathrm{SiO}_{2}(0,5-42,8 \%)$ e $\mathrm{MgO}$ $(0,1-3,5 \%)$.

Presentes na análise hidroquímica e relevantes para a diferenciação das águas circulantes nos membros Pedro Leopoldo e Lagoa Santa, as concentrações dos elementos traços $\mathrm{Ba}, \mathrm{F}$ e $\mathrm{S}$ foram analisados também nos calcários das referidas unidades. 
Tabela 1 - Resultados da difração de Raio-X das rochas aflorantes na área de estudo (Vieira, 2018).

\begin{tabular}{|c|c|c|c|c|c|c|c|c|c|c|c|c|}
\hline & \multicolumn{6}{|c|}{ Complexo Belo Horizonte } & \multicolumn{6}{|c|}{ Formação Serra de Santa Helena } \\
\hline$(\%)$ & \multicolumn{2}{|c|}{ Lu 017} & \multicolumn{2}{|c|}{ Lu 034} & \multicolumn{2}{|c|}{ Lu 078} & \multicolumn{2}{|c|}{ Lu 032} & \multicolumn{2}{|c|}{ Lu 080} & \multicolumn{2}{|c|}{ Lu 088} \\
\hline Quartzo $\left(\mathrm{SiO}_{2}\right)$ & \multicolumn{2}{|c|}{44,1} & \multicolumn{2}{|c|}{-} & \multicolumn{2}{|c|}{40,3} & \multicolumn{2}{|c|}{-} & \multicolumn{2}{|c|}{50,4} & \multicolumn{2}{|c|}{85,2} \\
\hline Quartzo low $\left(\mathrm{SiO}_{2}\right)$ & \multicolumn{2}{|c|}{-} & \multicolumn{2}{|c|}{29,7} & \multicolumn{2}{|c|}{ - } & \multicolumn{2}{|c|}{41,2} & \multicolumn{2}{|c|}{-} & \multicolumn{2}{|c|}{-} \\
\hline Oligoclásio (An10-30) & \multicolumn{2}{|c|}{47,1} & & & \multicolumn{2}{|c|}{-} & \multicolumn{2}{|c|}{-} & \multicolumn{2}{|c|}{-} & \multicolumn{2}{|c|}{-} \\
\hline Albita $\left(\mathrm{CaAl}_{2} \mathrm{Si}_{2} \mathrm{O}_{8}\right)$ & & & \multicolumn{2}{|c|}{62,7} & \multicolumn{2}{|c|}{39,1} & \multicolumn{2}{|c|}{15,7} & \multicolumn{2}{|c|}{-} & \multicolumn{2}{|c|}{-} \\
\hline Microclina $\left(\mathrm{KAISi}_{3} \mathrm{O}_{8}\right)$ & \multicolumn{2}{|c|}{8,4} & & & \multicolumn{2}{|c|}{8,3} & & & & & & 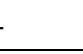 \\
\hline Ortoclásio $\left(\mathrm{KAlSi}_{3} \mathrm{O}_{8}\right)$ & & & & & & & & & & & & - \\
\hline $\begin{array}{c}\text { Clinocloro } \\
\left(\mathrm{Mg}_{5} \mathrm{Al}\right)\left(\mathrm{AlSi}_{3}\right) \mathrm{O}_{10}(\mathrm{OH})_{8}\end{array}$ & & & & & & & & & & & & 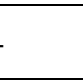 \\
\hline $\begin{array}{c}\text { Chamosita } \\
\left(\mathrm{Fe}_{5} \mathrm{Al}\right)\left(\mathrm{AlSi}_{3}\right) \mathrm{O}_{10}(\mathrm{OH})_{8}\end{array}$ & 0 & & & & & & & & & & & 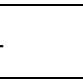 \\
\hline $\begin{array}{c}\text { Annita } \\
\left.\mathrm{KFe}_{3}{ }^{{ }^{2+}} \mathrm{AlSi}_{3} \mathrm{O}_{10}(\mathrm{OH})_{2}\right) \\
\end{array}$ & 0 & & & & & & & & & & & - \\
\hline $\begin{array}{c}\text { Phengita } \\
\left(\mathrm{K}(\mathrm{AlMg})_{2}(\mathrm{OH})_{2}(\mathrm{SiAl})_{4} \mathrm{O}_{10}\right)\end{array}$ & . & & & & & & & & & & & ,6 \\
\hline Caulinita $\left(\mathrm{Al}_{2} \mathrm{Si}_{2} \mathrm{O}_{5}(\mathrm{OH})_{4}\right.$ & - & & & & & & & & & & & 2 \\
\hline & & Memb & o Ped & o Leo & oldo & & & Me & bro I & agoa & nta & \\
\hline (\%) & $\begin{array}{c}\text { Lu } \\
016 A\end{array}$ & $\begin{array}{c}\text { Lu } \\
016 B\end{array}$ & $\begin{array}{c}\text { Lu } \\
020\end{array}$ & $\begin{array}{c}\text { Lu } \\
044\end{array}$ & $\begin{array}{c}\text { Lu } \\
054 \\
\end{array}$ & $\begin{array}{c}\text { Lu } \\
060\end{array}$ & $\begin{array}{c}\text { Lu } \\
019\end{array}$ & $\begin{array}{c}\text { Lu } \\
038 \\
\end{array}$ & $\begin{array}{c}\text { Lu } \\
043\end{array}$ & $\begin{array}{c}\text { Lu } \\
047\end{array}$ & $\begin{array}{l}\text { Lu } \\
051 \\
\end{array}$ & $\begin{array}{l}\text { Lu } \\
\mathbf{0 5 7}\end{array}$ \\
\hline Calcita $\left(\mathrm{CaCO}_{3}\right)$ & 100 & 78,1 & 72,2 & 87,2 & 92 & 79 & 100 & 100 & 100 & 100 & 100 & 98,4 \\
\hline Dolomita $\left(\mathrm{CaMgCO}_{3}\right)$ & - & - & - & 0,5 & - & 4,1 & - & - & - & - & - & - \\
\hline Quartzo $\left(\mathrm{SiO}_{2}\right)$ & - & 9,0 & 19,9 & - & 6,1 & - & - & - & - & - & - & 1,4 \\
\hline Quartzo low $\left(\mathrm{SiO}_{2}\right)$ & - & - & - & 8,1 & - & 8,7 & - & - & - & - & - & - \\
\hline $\begin{array}{c}\text { Phengita } \\
\left(\mathrm{K}(\mathrm{AlMg})_{2}(\mathrm{OH}, \mathrm{F})_{2}(\mathrm{SiAl})_{4} \mathrm{O}_{10}\right. \\
)\end{array}$ & - & 10,2 & 5,0 & 2,0 & 1,9 & 3,8 & - & - & - & - & - & - \\
\hline $\begin{array}{c}\text { Clinocloro } \\
\left(\mathrm{Mg}_{5} \mathrm{Al}\right)\left(\mathrm{AlSi}_{3}\right) \mathbf{O}_{10}(\mathrm{OH}, \mathrm{F})_{8}\end{array}$ & - & 2,8 & - & - & - & - & - & - & - & - & - & - \\
\hline $\begin{array}{c}\text { Clorita } \\
\left(\mathrm{Fe}_{5} \mathrm{Al}\right)\left(\mathrm{AlSi}_{3}\right) \mathrm{O}_{10}(\mathrm{OH}, \mathrm{F})_{8} \\
\end{array}$ & - & - & 2,9 & 2,1 & - & 4,4 & - & - & - & - & - & - \\
\hline
\end{tabular}

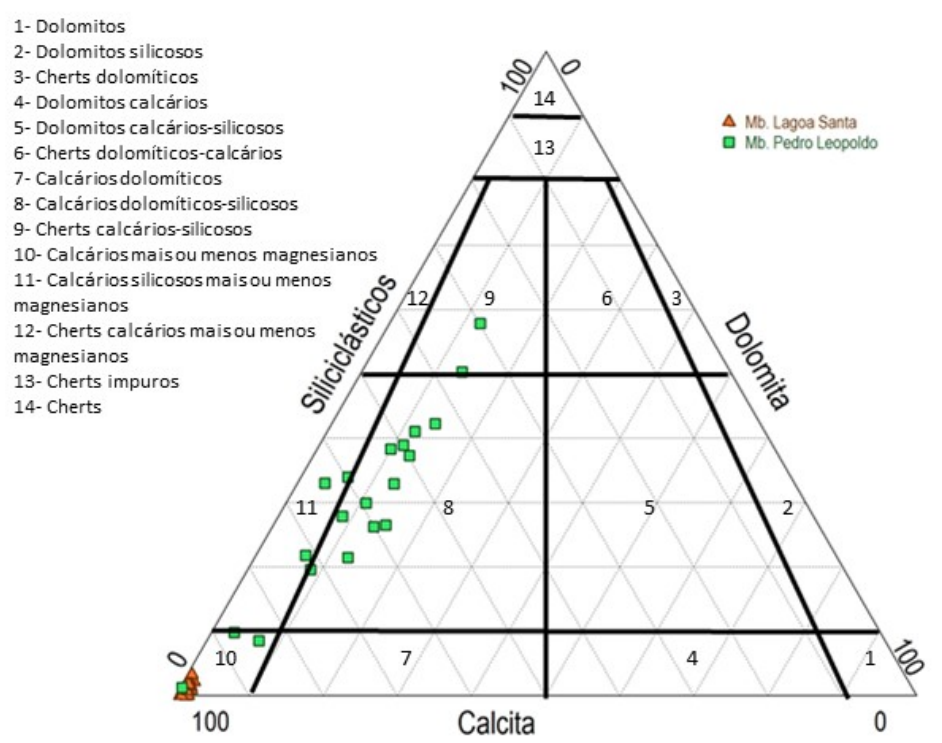

Figura 3 - Diagrama ternário da composição de calcita, dolomita e siliciclásticos dos calcários da Fm. Sete Lagoas na área estudada (Vieira et al., 2018).

De acordo com Vieira et al. (2018) as rochas carbonáticas do Membro Pedro Leopoldo detêm maiores teores de Ba em relação ao membro superior (61-830ppm e 29-196ppm, respectivamente), isso devido à afinidade deste elemento com sedimentos terrígenos (Lima et al., 2012), em maior quantidade nos calcários impuros. O Membro Lagoa Santa encerra os maiores teores 1092

São Paulo, UNESP, Geociências, v. 39, n. 4, p. 1087 - 1105, 2020 
de $S$ (0,01-0,06ppm), associados a presença de sulfetos disseminados $\left(\mathrm{FeS}_{2}\right)$, e de $\mathrm{F}$ (74-2704 ppm), na forma microcristalina de fluorita $\left(\mathrm{CaF}_{2}\right)$; as concentrações desses elementos no Membro Pedro Leopoldo abrangem os intervalos de 0,005-0,14ppm e 61-578ppm, respectivamente. Quanto ao F, além de estar associado a veios de calcita, pode ocorrer em filossilicatos, substituindo $\mathrm{OH}^{-}$na sua estrutura, como na Phengita $\left(\mathrm{K}(\mathrm{AlMg})_{2}(\mathrm{OH}, \mathrm{F})_{2}(\mathrm{SiAl})_{4} \mathrm{O}_{10}\right)$, Clinocloro ((Mg $\left.\mathrm{Mgl}_{5}\left(\mathrm{AlSi}_{3}\right) \mathrm{O}_{10}(\mathrm{OH}, \mathrm{F})_{8}\right)$ e Clorita $\left(\left(\mathrm{Fe}_{5} \mathrm{Al}\right) \quad\left(\mathrm{AlSi}_{3}\right) \mathrm{O}_{10}(\mathrm{OH}, \mathrm{F})_{8}\right)$, todos detectados na DRX das rochas do Membro Pedro Leopoldo.

\section{MÉTODOS}

A fim de se caracterizar quimicamente as águas representativas das litologias aquíferas locais, foram analisados parâmetros químicos, físico-químicos, hidráulicos e altimétricos referentes às águas de circulação rasa, representadas pelas nascentes (surgências e ressurgências), e de circulação profunda, a partir da amostragem em poços tubulares. As águas foram classificadas segundo as litologias nas quais percolam e os resultados obtidos tratados estatisticamente para comprovar a classificação prévia e a identificação de diferenças comportamentais entre as unidades aquíferas.

\section{Amostragem da Água}

Foram coletadas 23 amostras de águas de nascentes, incluindo uma duplicata, e 89 de poços tubulares operantes, compreendendo duas duplicatas. Tais pontos estenderam por mais $2 \mathrm{Km}$ desde os limites da área estudada. A amostragem das nascentes foi realizada no período de estiagem, de ago/2017 a set/2017, de modo a se caracterizar as águas de maior tempo de permanência nas zonas aquíferas; a amostragem dos poços ocorreu de out/2017 a fev/2018.

Nas nascentes, a coleta foi realizada o mais a montante possível e nos poços foi realizada após $10 \mathrm{~min}$. de bombeamento, caso se encontrasse parado. A coleta foi realizada com balde de aço inoxidável, frascos de polietileno transparentes e foscos, com uso de luvas descartáveis. Todos os recipientes e o multiparâmetro, utilizado para medição da condutividade elétrica (CE), sólidos totais dissolvidos (STD), temperatura ambiente (T), temperatura da amostra, $\mathrm{pH}$, ORP e resistividade, foram ambientados a cada coleta. Os métodos analíticos, técnicas de preservação e de amostragem estão detalhados na figura 4.

Os pontos foram pré-selecionados a partir do cadastro dos mesmos obtidos em bancos de dados disponibilizados pelo Sistema de Informações de Água Subterrâneas (SIAGAS), Companhia de Saneamento Básico de Minas Gerais (COPASA-MG) e Instituto Mineiro de Gestão das Águas (IGAM) através da Superintendência
Regional de Meio Ambiente (SUPRAM). Priorizaram-se os poços providos de perfis construtivo e litológico e as nascentes de maiores vazões.

\section{Tratamento dos Dados}

Todas as águas foram analisadas quanto às concentrações em mg/L dos íons maiores $\left(\mathrm{Ca}^{2+}\right.$, $\mathrm{Mg}^{2+}, \mathrm{Na}^{+}, \mathrm{K}^{+}, \mathrm{HCO}_{3}{ }^{-}, \mathrm{CO}_{3}{ }^{2-}, \mathrm{Cl}^{-}, \mathrm{SO}_{4}{ }^{2-}, \mathrm{Si}^{4+}$, , elementos traços (As total, $\mathrm{Ba}, \mathrm{Cd}, \mathrm{Pb}, \mathrm{Co}, \mathrm{Cu}$, $\mathrm{Cr}, \mathrm{Fe}, \mathrm{Mn}, \mathrm{Ni}, \mathrm{Ag}$, Th, U, V, Zn e F dissolvidos, $\mathrm{NO}_{3}^{-}, \mathrm{NO}_{2}^{-}, \mathrm{PO}_{4}{ }^{3-}$ ), aos parâmetros físicoquímicos $\mathrm{CE}, \mathrm{STD}, \mathrm{T}, \mathrm{pH}$ e Eh, às vazões e cota topográfica, estes dois últimos somente para os poços. Índices de saturação da calcita, dolomita, gipsita e gipsita semi-hidratada, foram obtidos por modelagem hidroquímica simples através do software PHREEQC.

Especificamente para os poços, foram analisadas também as cotas médias de entradas de água e capacidade específica (Qs). Dentre os elementos traços, apenas $\mathrm{Ba}^{2+}$ e $\mathrm{F}^{-}$foram trabalhados, pois os demais ficaram abaixo do limite de quantificação para todas as amostras. Para os casos em que a análise dos parâmetros ficou abaixo do limite de quantificação utilizouse metade do menor valor. A partir dos resultados fez-se o cálculo do balanço iônico de acordo com critério determinado por Logan (1965, segundo Santos, 2008) para avaliação da qualidade das análises e as amostras com erro prático maior que o admitido nesse trabalho (13\%) foram descartadas (1 nascente e 2 poços).

Entre as amostras cujas duplicatas foram analisadas, utilizou-se aquelas com menor erro.

Os pontos foram pré-selecionados a partir do cadastro dos mesmos obtidos em bancos de dados disponibilizados pelo Sistema de Informações de Água Subterrâneas (SIAGAS), Companhia de Saneamento Básico de Minas Gerais (COPASA-MG) e Instituo Mineiro de Gestão das Águas (IGAM) através da Superintendência Regional de Meio Ambiente (SUPRAM). Priorizaram-se os poços providos de perfis construtivo e litológico, e as nascentes de maiores vazões. 


\begin{tabular}{|c|c|c|c|c|c|c|c|}
\hline Parâmetros & $\begin{array}{c}\text { Método de } \\
\text { Amostragem }\end{array}$ & Preservação & $\begin{array}{l}\text { Método } \\
\text { Analítico }\end{array}$ & $\begin{array}{c}\text { Prazo } \\
\text { Análise }\end{array}$ & \begin{tabular}{|c|} 
Volume \\
Amostra \\
$(\mathrm{mL})$
\end{tabular} & $\begin{array}{l}\text { Tipo de } \\
\text { Frasco }\end{array}$ & Método \\
\hline \begin{tabular}{|c} 
pH, Condutividade, \\
Resistividade, \\
Sólidos Totais \\
Dissolvidos (STD), \\
Eh (pE) \\
\end{tabular} & $\begin{array}{l}\text { in loco - } \\
\text { multiparâmetro }\end{array}$ & $\begin{array}{c}\text { Refrigeração em caixa } \\
\text { com gelo até entrega } \\
\text { ao laboratório }\end{array}$ & - & 2 horas & - & - & $\begin{array}{l}\text { Multipa- } \\
\text { râmetro }\end{array}$ \\
\hline $\begin{array}{c}\text { Temperatura da } \\
\text { Água, } \\
\text { Temperatura } \\
\text { Ambiente } \\
\end{array}$ & $\begin{array}{l}\text { in loco - } \\
\text { multiparâmetro }\end{array}$ & - & - & - & - & - & $\begin{array}{l}\text { Multipa- } \\
\text { râmetro }\end{array}$ \\
\hline Turbidez & \multirow{8}{*}{$\begin{array}{c}\text { Coleta em balde } \\
\text { ambientado e } \\
\text { homogeneizado, } \\
\text { armazenamento } \\
\text { em frasco } \\
\text { ambientado. No } \\
\text { caso de água } \\
\text { subterrânea (coleta } \\
\text { em poço) ativar } \\
\text { bombeamento de } \\
\text { poço quando } \\
\text { parado, espera de } \\
10 \text { min após } \\
\text { ativação de } \\
\text { bombeamento, } \\
\text { seguindo a } \\
\text { seguinte ordem de } \\
\text { prioridade do local } \\
\text { de coleta (torneira, } \\
\text { saída direto do } \\
\text { cano, cano antes } \\
\text { de cair na caixa } \\
\text { d'água) }\end{array}$} & \begin{tabular}{|c|} 
Refrigeração em caixa \\
com gelo até entrega \\
ao laboratório
\end{tabular} & $\begin{array}{l}2130 \text { B - } \\
\text { Turbidez }\end{array}$ & $\begin{array}{c}24 \\
\text { Horas }\end{array}$ & 500 & $\begin{array}{c}\text { Polietileno } \\
\text { Transparente }\end{array}$ & - \\
\hline STD & & \begin{tabular}{|c|} 
Refrigeração em caixa \\
com gelo até entrega \\
ao laboratório \\
\end{tabular} & $\begin{array}{l}2540 \text { C - } \\
\text { Sólidos }\end{array}$ & 7 dias & 500 & $\begin{array}{c}\text { Polietileno } \\
\text { Transparente }\end{array}$ & - \\
\hline $\begin{array}{c}\text { Alcalinidade de } \\
\text { Bicarbonato, } \\
\text { Alcalinidade de } \\
\text { Carbonato } \\
\end{array}$ & & \begin{tabular}{|c} 
Refrigeração em caixa \\
com gelo até entrega \\
ao laboratório
\end{tabular} & $\begin{array}{c}2320 \text { B - } \\
\text { Alcalinidade }\end{array}$ & $\begin{array}{c}24 \\
\text { horas }\end{array}$ & 500 & $\begin{array}{l}\text { Polietileno } \\
\text { Transparente }\end{array}$ & - \\
\hline $\mathrm{Cl}^{-}, \mathrm{F}^{-}, \mathrm{SO}_{4}{ }^{2-}, \mathrm{SiO}_{2}$ & & $\begin{array}{c}\text { Refrigeração em caixa } \\
\text { com gelo até entrega } \\
\text { ao laboratório }\end{array}$ & \begin{tabular}{|c|}
4110 B - \\
Determinação \\
de ânions por \\
cromatografia \\
de íons \\
\end{tabular} & 28 dias & 500 & $\begin{array}{c}\text { Polietileno } \\
\text { Transparente }\end{array}$ & - \\
\hline $\mathrm{NO}_{3}{ }^{-}, \mathrm{NO}_{2}{ }^{-}$ & & $\begin{array}{c}\text { Refrigeração em caixa } \\
\text { com gelo até entrega } \\
\text { ao laboratório }\end{array}$ & \begin{tabular}{|c|}
4110 B - \\
Determinação \\
de ânions por \\
cromatografia \\
de íons \\
\end{tabular} & $\begin{array}{c}48 \\
\text { horas }\end{array}$ & 250 & $\begin{array}{c}\text { Polietileno } \\
\text { Transparente }\end{array}$ & - \\
\hline $\mathrm{PO}_{4}{ }^{3-}$ & & $\begin{array}{c}\text { Refrigeração em caixa } \\
\text { com gelo até entrega } \\
\text { ao laboratório }\end{array}$ & \begin{tabular}{|c|}
3120 B - \\
Metais por \\
espectroscopia \\
de emissão de \\
plasma \\
\end{tabular} & $\begin{array}{c}48 \\
\text { horas }\end{array}$ & 250 & $\begin{array}{l}\text { Polietileno } \\
\text { Transparente }\end{array}$ & - \\
\hline $\begin{array}{c}\text { As, } T h, U \text { (Metais } \\
\text { totais) }\end{array}$ & & $\begin{array}{c}\text { Adição de ácido } \\
\text { nítrico }\end{array}$ & $\begin{array}{c}3125 \text { B - } \\
\text { Metais por } \\
\text { plasma } \\
\text { indutivamente } \\
\text { acoplado/espec } \\
\text { trometria de } \\
\text { massa } \\
\end{array}$ & 6 meses & 500 & $\begin{array}{l}\text { Polietileno } \\
\text { Fosco }\end{array}$ & - \\
\hline $\begin{array}{c}\text { Ca, Mg, Na, K, Ba, } \\
\text { Cd, Pb, Co, Cu, Cr, } \\
\text { Fe, F, Mn, Ni, Ag, } \\
\text { V, Zn (Metais } \\
\text { Solúveis) }\end{array}$ & & $\begin{array}{c}\text { Filtração em } \\
\text { membrana (45 mesh) } \\
\text { e adição de ácido } \\
\text { nítrico }\end{array}$ & \begin{tabular}{|c|}
3120 B - \\
Metais por \\
espectroscopia \\
de emissão de \\
plasma
\end{tabular} & 6 meses & 500 & $\begin{array}{c}\text { Polietileno } \\
\text { Fosco }\end{array}$ & - \\
\hline
\end{tabular}

Figura 4 - Métodos analíticos, de amostragem e de preservação de água de nascentes e poços tubulares.

\section{Tratamento dos Dados}

Todas as águas foram analisadas quanto às concentrações em mg/L dos íons maiores $\left(\mathrm{Ca}^{2+}\right.$, $\left.\mathrm{Mg}^{2+}, \mathrm{Na}^{+}, \mathrm{K}^{+}, \mathrm{HCO}_{3}{ }^{-}, \mathrm{CO}_{3}{ }^{2-}, \mathrm{Cl}^{-}, \mathrm{SO}_{4}{ }^{2-}, \mathrm{Si}^{4+}\right)$, elementos traços (As total, $\mathrm{Ba}, \mathrm{Cd}, \mathrm{Pb}, \mathrm{Co}, \mathrm{Cu}$, Cr, Fe, Mn, Ni, Ag, Th, U, V, Zn e F dissolvidos, $\mathrm{NO}_{3}{ }^{-}, \mathrm{NO}_{2}{ }^{-}, \mathrm{PO}_{4}{ }^{3-}$ ), aos parâmetros físicoquímicos CE, STD, T, pH e Eh, às vazões e cota topográfica, estes dois últimos somente para os poços. Índices de saturação da calcita, dolomita, gipsita e gipsita semi-hidratada, foram obtidos por modelagem hidroquímica simples através do software PHREEQC.

Especificamente para os poços, foram analisadas também as cotas médias de entradas de água e capacidade específica (Qs). Dentre os elementos traços, apenas $\mathrm{Ba}^{2+}$ e $\mathrm{F}^{-}$foram trabalhados, pois os demais ficaram abaixo do limite de quantificação para todas as amostras. Para os casos em que a análise dos parâmetros ficou abaixo do limite de quantificação utilizouse metade do menor valor. 
A partir dos resultados fez-se o cálculo do balanço iônico de acordo com critério determinado por Logan (1965, segundo Santos, 2008) para avaliação da qualidade das análises e as amostras com erro prático maior que o admitido nesse trabalho (13\%) foram descartadas (1 nascente e 2 poços). Entre as amostras cujas duplicatas foram analisadas, utilizou-se aquelas com menor erro.

As águas foram classificadas segundo as unidades aquíferas procedentes. Para os poços a classificação ocorreu com base na análise química, geologia aflorante, descrição litológica e profundidades de entradas d’água do perfil do poço. A classificação das nascentes foi realizada a partir da geologia aflorante e, secundariamente, por meio da análise da hidroquímica.

O tratamento dos dados das águas das nascentes e dos poços foi realizado separadamente, porém da mesma forma. A determinação e análise das fácies hidroquímicas ocorreu segundo os diagramas de Piper e Stiff e uma caracterização mais detalhada foi realizada em gráficos binários e ternários, usando-se o software DIAGRAMMES, disponibilizado por Miche et al. (2013) e Excel (Microsoft Office Professional Plus, 2013).

Como auxílio na interpretação dos processos e características hidroquímicas, foram gerados mapas de isoconcentrações químicas e físicoquímicas e de dados físicos (altimetria) e hidráulicos (vazão), utilizando o método de interpolação do inverso da distância ao quadrado, por meio do software QGis (versão 2.8.9). As relações entre todas as variáveis foram obtidas por meio de matrizes de correlação a partir de coeficientes de correlação de Pearson e Spearman calculados pelo software STATISTICA. Para se evitar a influência de valores extremos nos resultados, optou-se por se adotar a mediana como valor representativo em cada conjunto de dados.

\section{RESULTADOS E DISCUSSÕES}

\section{Zonas Aquíferas Subsuperficiais - Nascentes}

A maior parte das nascentes (Tabela 2) corresponde a surgências e ressurgências cársticas em níveis superiores do sistema aquífero, com rápido tempo de trânsito (Teodoro et al., 2018, no prelo) instaladas nos calcários calcíticos carstificados do Membro Lagoa Santa (13) e nos calcários impuros do Membro Pedro Leopoldo (5). Tem-se ainda duas em granitoides e uma em cobertura detrito-laterítica.

Apesar da alta velocidade de trânsito dessas águas elas se apresentam, em geral, altamente salinizadas ( $\mathrm{STD}=227 \mathrm{mg} / \mathrm{L}$ ), denotando a alta solubilidade dos calcários. As águas associadas aos calcários puros do Membro Lagoa Santa possuem, como esperado, concentrações um pouco maiores de STD $(240,9 \mathrm{mg} / \mathrm{L})$ em relação às do Membro Pedro Leopoldo (218,8mg/L). Os valores mais baixos correspondem aos granitoides, $79,62 \mathrm{mg} / \mathrm{L}$ e $59,75 \mathrm{mg} / \mathrm{L}$ e à cobertura detrito-laterítica, 10,65mg/L.

A salinização das águas é controlada pelos íons $\mathrm{Ca}^{2+}$ e $\mathrm{HCO}_{3}{ }^{-}$, especialmente naquelas dos aquíferos carbonáticos $(\mathrm{R}=0,93$ e $\mathrm{R}=0,92$, respectivamente - figura 5 ). Tais íons são responsáveis pela fácies bicarbonatada cálcica com exceção de uma única amostra associada ao granito classificada como bicarbonatada mista, Nas-Frigovitor, (Figura 6).

A composição silicática dos granitos (micas, microclina, ortoclásio e quartzo - Tabela 1), refletida na hidroquímica de suas nascentes, permite uma clara diferenciação dessas águas comparadas àquelas oriundas das rochas carbonáticas do Membro Pedro Leopoldo e Lagoa Santa (Figura 7). A dissolução de micas e quartzo da porção pelítica do membro inferior, proporciona concentrações maiores de $\mathrm{Na}^{+}$e $\mathrm{Si}^{4+}$ a suas águas quando comparadas às nascentes do Membro Lagoa Santa, o que torna esses parâmetros relevantes para a distinção dessas águas entre os membros (Figura 7).

Em razão dos teores variáveis de calcita, dolomita e siliciclásticos das rochas do Membro Pedro Leopoldo (Figura 3) a composição hídrica é também diversificada, principalmente quanto à $\mathrm{Si}^{4+}$ e $\mathrm{Mg}^{2+}$.

Excluindo a região dos granitos a sudoeste, as maiores concentrações destes íons, estão localizadas ao longo do limite leste da área (Figura 8A), em que se verificam rochas do Membro Pedro Leopoldo com maior frequência de intercalações pelíticas entre os pacotes carbonáticos, teores elevados de $\mathrm{SiO}_{2}$ e $\mathrm{MgO}$, e com dolomita (Vieira et al., 2018).

As vazões pouco expressivas das nascentes relacionadas com o Membro Pedro Leopoldo $\left(60,1 \mathrm{~m}^{3} / \mathrm{h}\right)$ em relação àquelas do Membro Lagoa Santa $\left(181,3 \mathrm{~m}^{3} / \mathrm{h}\right)$ reflete também a variedade composicional dos calcários do primeiro membro 
Tabela 2 - Resultados analíticos das amostras de nascentes na área de estudo.

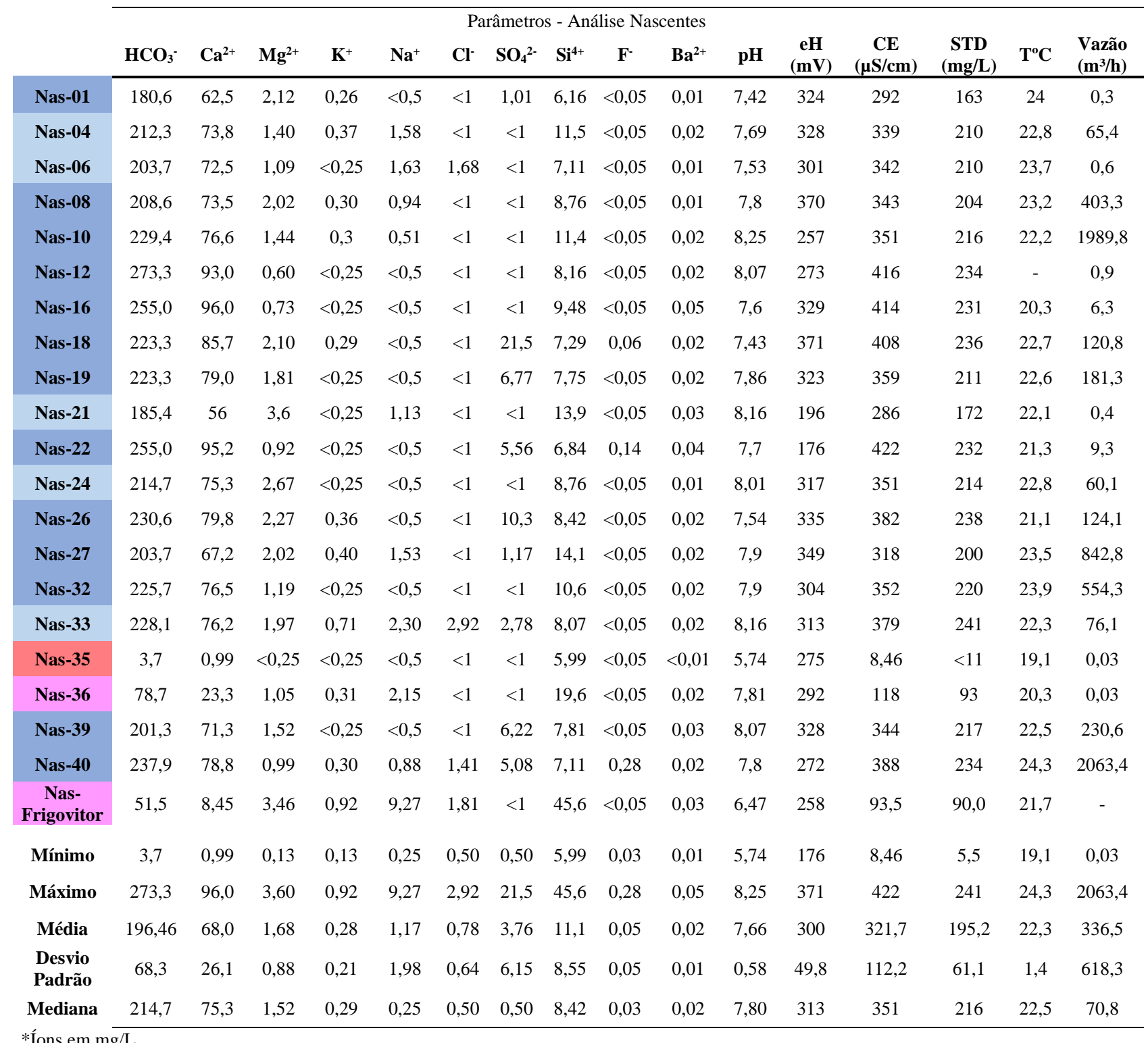

*Íons em mg/L

Rosa $=$ Complexo Belo Horizonte, Azul claro = Membro Pedro Leopoldo, Azul escuro = Membro Lagoa Santa, Vermelho = Cobertura Detritolaterítica.

\begin{tabular}{|c|c|c|c|c|c|c|c|c|c|c|c|c|c|c|c|}
\hline & $\mathrm{Ca}^{2+}$ & $\mathbf{M g}^{2+}$ & $\mathbf{K}^{+}$ & $\mathbf{N a}^{+}$ & $\mathrm{HCO}_{3}{ }^{-}$ & $\mathrm{Cl}^{-}$ & $\mathrm{SO}_{4}{ }^{2-}$ & $\mathbf{B a}^{2+}$ & $\mathrm{Si}^{4+}$ & $F^{-}$ & pH & STD & Vazão & Eh & $T$ água \\
\hline $\mathrm{Ca}^{2+}$ & 1,00 & $-0,67$ & $-0,14$ & $-0,42$ & 0,91 & $-0,07$ & 0,34 & 0,47 & $-0,44$ & 0,26 & $-0,19$ & 0,93 & $-0,08$ & $-0,05$ & $-0,56$ \\
\hline $\mathrm{Mg}^{2+}$ & $-0,67$ & 1,00 & 0,18 & 0,13 & $-0,68$ & $-0,09$ & 0,14 & $-0,29$ & 0,34 & $-0,30$ & 0,16 & $-0,59$ & $-0,21$ & 0,06 & 0,15 \\
\hline $\mathbf{K}^{+}$ & $-0,14$ & 0,18 & 1,00 & 0,62 & $-0,08$ & 0,60 & 0,14 & $-0,26$ & 0,05 & 0,00 & 0,09 & 0,08 & 0,17 & 0,34 & 0,13 \\
\hline $\mathrm{Na}^{+}$ & $-0,42$ & 0,13 & 0,62 & 1,00 & $-0,29$ & 0,71 & $-0,33$ & $-0,23$ & 0,33 & $-0,07$ & 0,19 & $-0,28$ & 0,03 & 0,04 & 0,25 \\
\hline $\mathrm{HCO}_{3}{ }^{-}$ & 0,91 & $-0,68$ & $-0,08$ & $-0,29$ & 1,00 & 0,03 & 0,10 & 0,45 & $-0,24$ & 0,31 & 0,07 & 0,92 & 0,10 & $-0,22$ & $-0,60$ \\
\hline $\mathrm{Cl}^{-}$ & $-0,07$ & $-0,09$ & 0,60 & 0,71 & 0,03 & 1,00 & $-0,11$ & $-0,17$ & $-0,24$ & 0,17 & 0,15 & 0,07 & 0,05 & $-0,02$ & 0,18 \\
\hline $\mathrm{SO}_{4}{ }^{2-}$ & 0,34 & 0,14 & 0,14 & $-0,33$ & 0,10 & $-0,11$ & 1,00 & 0,03 & $-0,42$ & 0,23 & $-0,32$ & 0,45 & $-0,10$ & 0,26 & $-0,01$ \\
\hline $\mathrm{Ba}^{2+}$ & 0,47 & $-0,29$ & $-0,26$ & $-0,23$ & 0,45 & $-0,17$ & 0,03 & 1,00 & 0,14 & 0,14 & 0,04 & 0,42 & $-0,12$ & $-0,39$ & $-0,66$ \\
\hline $\mathrm{Si}^{4^{+}}$ & $-0,44$ & 0,34 & 0,05 & 0,33 & $-0,24$ & $-0,24$ & $-0,42$ & 0,14 & 1,00 & $-0,35$ & 0,45 & $-0,36$ & 0,19 & $-0,12$ & $-0,07$ \\
\hline $\mathrm{F}^{-}$ & 0,26 & $-0,30$ & 0,00 & $-0,07$ & 0,31 & 0,17 & 0,23 & 0,14 & $-0,35$ & 1,00 & $-0,12$ & 0,35 & 0,53 & $-0,34$ & 0,26 \\
\hline pH & $-0,19$ & 0,16 & 0,09 & 0,19 & 0,07 & 0,15 & $-0,32$ & 0,04 & 0,45 & $-0,12$ & 1,00 & $-0,07$ & 0,31 & $-0,37$ & $-0,11$ \\
\hline STD & 0,93 & $-0,59$ & 0,08 & $-0,28$ & 0,92 & 0,07 & 0,45 & 0,42 & $-0,36$ & 0,35 & $-0,07$ & 1,00 & 0,06 & $-0,05$ & $-0,53$ \\
\hline Vazão & $-0,08$ & $-0,21$ & 0,17 & 0,03 & 0,10 & 0,05 & $-0,10$ & $-0,12$ & 0,19 & 0,53 & 0,31 & 0,06 & 1,00 & $-0,12$ & 0,36 \\
\hline Eh & $-0,05$ & 0,06 & 0,34 & 0,04 & $-0,22$ & $-0,02$ & 0,26 & $-0,39$ & $-0,12$ & $-0,34$ & $-0,37$ & $-0,05$ & $-0,12$ & 1,00 & 0,25 \\
\hline$T$ água & $-0,56$ & 0,15 & 0,13 & 0,25 & $-0,60$ & 0,18 & $-0,01$ & $-0,66$ & $-0,07$ & 0,26 & $-0,11$ & $-0,53$ & 0,36 & 0,25 & 1,00 \\
\hline
\end{tabular}

Figura 5 - Matriz correlação das águas de nascentes em calcários dos Membros Pedro Leopoldo e Lagoa Santa. 


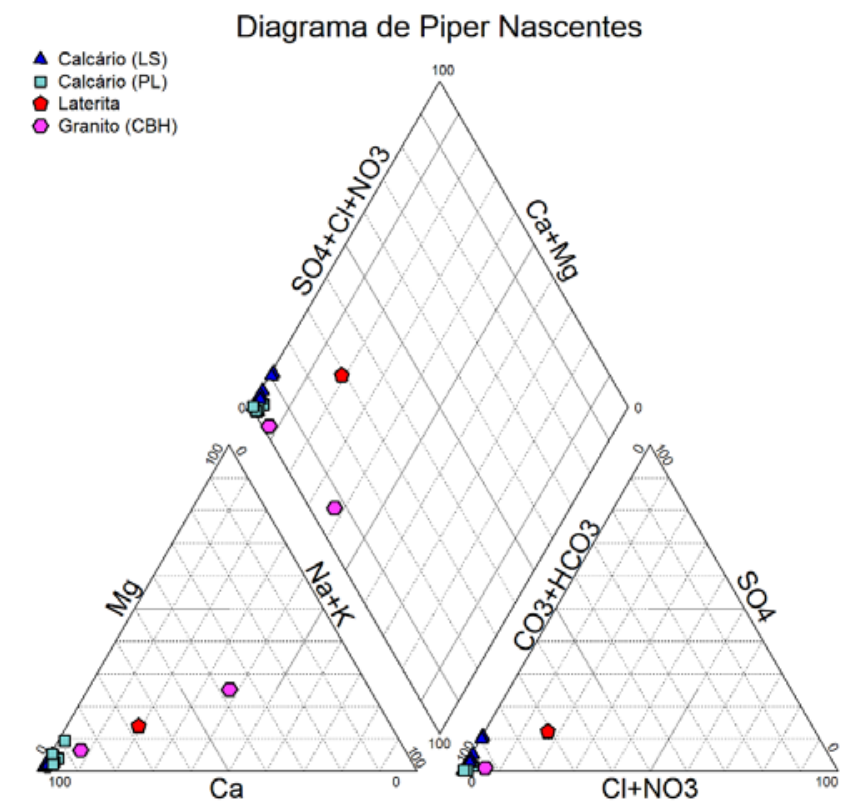

Figura 6 - Diagrama de Piper para as águas de nascentes na área do projeto (Vieira, 2018).

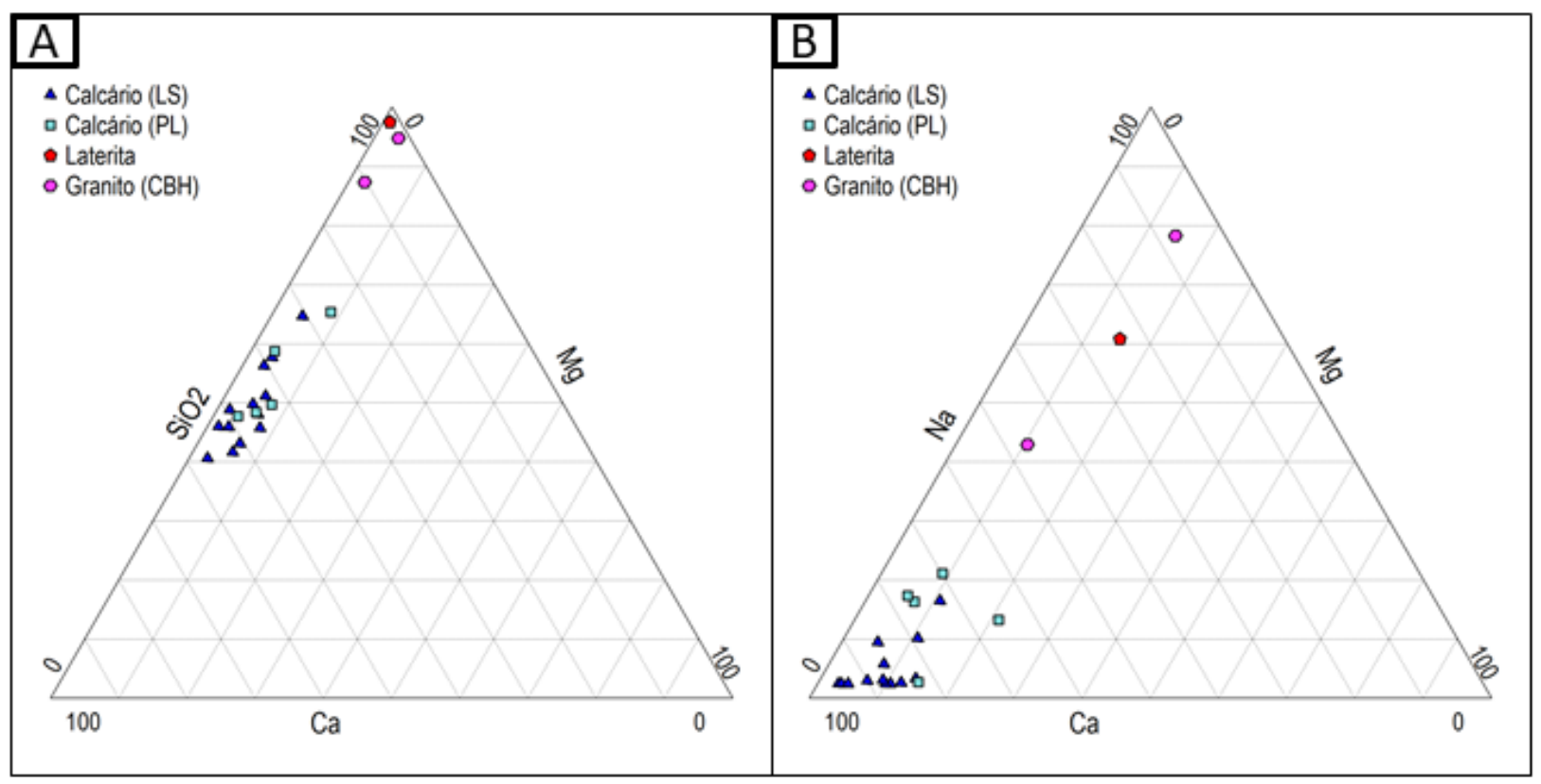

Figura 7 - Diagramas ternários para as nascentes da região da APA Carste de Lagoa Santa, separadas segundo classificação hidrogeológica: A) Ca-Mg-SiO 2 e B) Ca-Mg-Na (Vieira, 2018).

(Figura 8B), cuja presença de intercalações pelíticas reduz a susceptibilidade aos processos de dissolução cárstica. Contrariamente, a pureza composicional maiormente calcítica do calcário Lagoa Santa proporciona maior susceptibilidade à dissolução cárstica $\left(\mathrm{Ca}^{2+}=78,8 \mathrm{mg} / \mathrm{L}^{2} \mathrm{HCO}_{3}{ }^{-}\right.$ $=225,7 \mathrm{mg} / \mathrm{L})$, explicando as vazões mais elevadas.

Na medida em que os calcários do Membro Lagoa Santa exibem teores maiores de S e F do que as rochas do Membro Pedro Leopoldo, suas águas também resultam em concentrações mais elevadas de $\mathrm{SO}_{4}{ }^{2-}(1,17 \mathrm{mg} / \mathrm{L})$ e $\mathrm{F}^{-}(0,03 \mathrm{mg} / \mathrm{L})$ do que aquelas da segunda unidade, com 0,5 e
$0,025 \mathrm{mg} / \mathrm{L}$, respectivamente. Os íons $\mathrm{SO}_{4}{ }^{2-}$ contribuem com a salinidade da água $(\mathrm{R}=0,45)$, e estão relacionados, dentre outros fatores, à oxidação de sulfetos nas rochas, mais precisamente da pirita, encontrada de forma disseminada e predominantemente nos calcários do Membro Lagoa Santa, como mostrado na litoquímica a partir da concentração de S (Vieira et al., 2018). Além disso, podem se relacionar também com a lixiviação de compostos sulfatados, como por exemplo, gipsita e anidrita.

A tendência de vazões mais elevadas ocorrerem em calcários mais puros é indicada também de forma indireta, através da correlação 


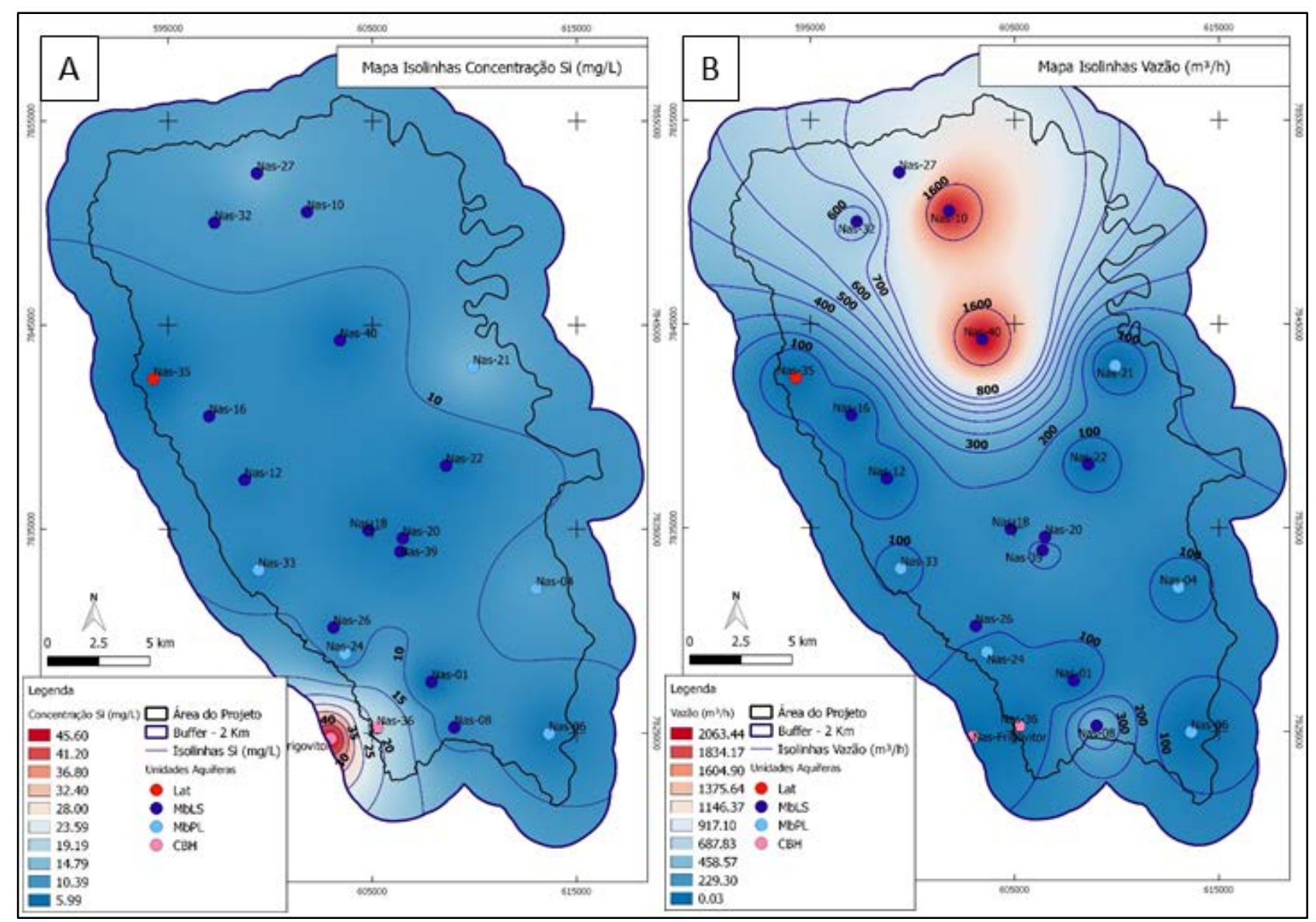

Figura 8 - Mapas de Isolinhas de águas de nascentes para: A) Concentração, em mg/L, de $\mathrm{Si}^{4+}$; e B) Vazão, em m³/h (Vieira, 2018).

moderada entre vazão e $\mathrm{F}^{-}(\mathrm{R}=0,53)$ e a associação deste íon com concentrações mais altas de $\mathrm{Ca}^{2+}$ e $\mathrm{HCO}_{3}^{-}(\mathrm{R}=0,26$ e $\mathrm{R}=0,31$, respectivamente).

Considera-se que outras variáveis além da litoquímica, como os tipos de falhas, fraturas, gradiente hidráulico, dentre outras, sejam também determinantes na carstificação e, consequentemente, na vazão, em cada membro hidroestratigráfico.

\section{Zonas Aquíferas Profundas - Poços}

As águas extraídas dos poços tubulares representam as zonas de circulação profunda das unidades aquíferas, compostas pelo Complexo Belo Horizonte (6), Membro Pedro Leopoldo (43), Membro Lagoa Santa (26), Fm. Serra de Santa Helena (3), colúvio (1), mistura de águas do Complexo Belo Horizonte e do Membro Pedro Leopoldo (1), mistura de águas provenientes do Membro Lagoa Santa e Formação Serra de Santa Helena (5). As concentrações iônicas e de parâmetros físicoquímicos e de vazão se encontram na tabela 3 .

A dissolução da calcita nos íons $\mathrm{Ca}^{2+}$ e $\mathrm{HCO}_{3}{ }^{-}$ é responsável pela elevada salinização $(217 \mathrm{mg} / \mathrm{L})$ das zonas aquíferas profundas
( $\mathrm{R}=0,89$ e $\mathrm{R}=0,93$, respectivamente) (Figura 9). Dessa forma, o Membro Lagoa Santa, formado essencialmente por calcita, é o maior contribuinte (255mg/L) para tal salinização. Assim, prevalece as águas bicarbonatadas cálcicas (80), seguida das bicarbonatadas mistas relativas aos granitos (6) e bicarbonatada sódica associada ao colúvio (1) (Figura 10).

A presença de $\mathrm{SO}_{4}{ }^{2-}$ nas águas do Membro Lagoa Santa a partir da oxidação de sulfetos em suas rochas e da lixiviação de compostos sulfatados, como gipsita e anidrita, através dos sedimentos da Fm. Serra de Santa Helena, sobreposta, provoca maiores concentrações deste íon $(2,89 \mathrm{mg} / \mathrm{L})$ nas águas mistas dessas duas unidades.

A maior solubilidade de calcita e sua maior ocorrência no membro superior, resulta também numa maior liberação de íons de $\mathrm{Ba}^{2+}$ para as suas águas $(0,04 \mathrm{mg} / \mathrm{L})$, uma vez que mormente substitui o $\mathrm{Ca}^{2+}$ na estrutura deste mineral (Batista \& Santos Filho, 2016).

A variação composicional quanto ao teor de calcita, dolomita e siliciclásticos nos calcários impuros do Membro Pedro Leopoldo (Figura 3) se torna ainda mais evidente nas zonas aquíferas 
Tabela 3 - Resultados analíticos das amostras de água subterrânea em poços da área estudada.

\begin{tabular}{|c|c|c|c|c|c|c|c|c|c|c|c|c|c|c|c|c|}
\hline & \multicolumn{15}{|c|}{ Parâmetros - Análise Poços } & \\
\hline & $\mathrm{ICO}_{3}$ & $\mathrm{Ca}^{2+}$ & $\mathbf{M g}^{2+}$ & $\mathbf{K}^{+}$ & $\mathrm{Na}^{+}$ & $\mathrm{Cl}^{-}$ & $\mathrm{S}$ & $\mathrm{Ba}^{2+}$ & $\mathrm{Si}^{4+}$ & $\mathbf{F}^{-}$ & pH & $\begin{array}{l}\text { eH } \\
\mathrm{mV} \text { ) }\end{array}$ & \begin{tabular}{|c|}
$\mathrm{CE}$ \\
$(\mu \mathrm{S} / \mathrm{cm})$
\end{tabular} & \begin{tabular}{|c|} 
STD \\
$(\mathrm{mg} / \mathrm{L})$
\end{tabular} & $\Gamma^{\circ} \mathbf{C}$ & $\begin{array}{l}\text { Vazão } \\
\left.\mathbf{m}^{3} / \mathbf{h}\right)\end{array}$ \\
\hline 009 & 0,10 & 64,3 & & 0,44 & 4,77 & $<1$ & 4,9 & & & 5 & 7,18 & 51 & 383 & 49,3 & 24,4 & 2,9 \\
\hline 00069-PT & 19,64 & 119 & 0,49 & $<0,25$ & $<0,5$ & $<1$ & 1,69 & 0,08 & 5,12 & 0,51 & 7,09 & 388 & 485,9 & 318,8 & 24,5 & - \\
\hline 00086-2008 & 54,98 & 92,3 & ,91 & 0,29 & $<0,5$ & $<1$ & $<1$ & 0,04 & 13,5 & 0,06 & 7,57 & 303 & 387,7 & 253,7 & 26,4 & - \\
\hline 00215-2008 & 35,44 & 52,6 & 4,42 & $<0,25$ & 0,62 & $<1$ & $<1$ & $<0,01$ & 12,4 & $<0,05$ & 7,87 & 379 & 286,3 & 185,1 & 24,4 & 3,3 \\
\hline 00301-2007 & 25,66 & 21,20 & 7,41 & 1,02 & 10,30 & $<1$ & $<1$ & 0,02 & 49,9 & 0,21 & 6,64 & 187 & 197,7 & 127,4 & 24,50 & 6,0 \\
\hline 00824-2003 & 13,50 & 77,6 & 2,02 & 0,29 & 3,18 & 1,94 & $<1$ & 0,01 & 11,7 & $<0,05$ & 7,11 & 370 & 341,5 & 224,9 & 23,4 & 4,7 \\
\hline 00886-2002 & 2,72 & 15,8 & 5,29 & 1,45 & 12,7 & $<1$ & $<1$ & 0,03 & 61,2 & 0,19 & 6,19 & 295 & 149 & 94,51 & 23,3 & 13,8 \\
\hline 01360-2009 & 51,32 & 96,7 & 0,37 & $<0,25$ & $<0,5$ & $<1$ & $<1$ & 0 & 7,75 & 0,05 & 7,65 & 25 & 379,9 & 250,2 & 4,6 & - \\
\hline 01361-2009 & 35,46 & 91 & 0,81 & 0,5 & $<0,5$ & $<1$ & $<1$ & 0,04 & 10,6 & $<0,05$ & 7,29 & 405 & 352,5 & 238,2 & 24,7 & 4,5 \\
\hline 01378-2003 & 106,99 & 22,70 & 5,04 & $0, \mathrm{~s}$ & 5,75 & $<1$ & $<1$ & & 34,5 & 0,05 & 6,76 & 267 & 187 & 11,7 & 3,50 & ,2 \\
\hline 01584-2008 & 31,76 & 20 & 5,54 & 1,87 & 15,3 & 7,48 & $<1$ & 0,09 & 32,1 & $<0,05$ & 6,1 & 184 & 235,7 & 152,1 & 24,2 & 5,0 \\
\hline 02289-2009 & 59,82 & 65,3 & 3,17 & 068 & 3,86 & 18,7 & 6,83 & 0,0 & 5,81 & $<0,05$ & 7,19 & 184 & 356,5 & 32,3 & 7,5 & 6,0 \\
\hline 03057-PT & 121,15 & 37,4 & 6,35 & $<0,25$ & 0,58 & $<1$ & $<1$ & 0,01 & 14,5 & $<0,05$ & 6,88 & 326 & 199,6 & 128,2 & 23,5 & 40,0 \\
\hline 03070-PT & 290,36 & 0,0 & 6,76 & 0,25 & 2,34 & 3,69 & 2,26 & 0,02 & 14,3 & $<0,05$ & 7,35 & 771 & 61,7 & 07,1 & 24,6 & 216 , \\
\hline 03075-PT & 99,67 & 34,7 & 1,12 & $<0,25$ & 1,03 & 1,38 & $<1$ & 0,02 & 10,4 & 0,19 & 6,68 & 363 & 169,9 & 108,1 & 24,3 & 12,0 \\
\hline 03086-PT & 9,78 & 17 & 1,5 & 0,25 & 0,5 & $<1$ & $<1$ & 1 & 54 & 0,19 & 7,7 & 95 & 14,4 & 2,51 & 2,1 & 5,3 \\
\hline 03088-PT & 5,64 & 27,8 & 2,67 & $<0,25$ & 0 , & $<1$ & $<1$ & $<0$, & 10 & 0,05 & 6,54 & 252 & 47,1 & 92,77 & 25,4 & 10,0 \\
\hline 03100-PT-2 & 8,54 & 0,26 & 0,25 & $<0,25$ & 4,04 & 1,48 & $<1$ & $<0,01$ & 9,80 & $<0,05$ & 5,08 & 336 & 38,81 & 24,69 & 25,7 & - \\
\hline 03104-PT & 211,06 & 6 & 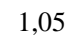 & $<$ & 1,35 & 1,49 & $<1$ & $<0,01$ & 8,5 & 05 & 7,57 & 343 & 38,8 & 23 & 22,5 & 7,0 \\
\hline 03127-PT & 262,30 & 80,1 & 0,61 & 0,26 & $<0,5$ & 1,58 & 1,78 & 0,05 & 6,51 & $<0,05$ & 7,44 & 426 & 406,9 & 270,3 & 23,4 & 18,0 \\
\hline 03136 & 6,94 & 110 & & 5 & 5 & $<1$ & 1,11 & & 9,02 & 1 & 8 & 262 & 35,1 & 89,3 & 24,5 & - \\
\hline 03140-PT & 284,26 & 04 & 0,64 & $<0,25$ & $<0,5$ & $<1$ & 1,32 & 0 & 8,72 & 0,16 & 8,12 & 25 & 447,1 & 296,8 & 25,3 & 0,3 \\
\hline 03151-PT & 206,18 & 9,30 & 97 & $<0,25$ & 0,5 & $<1$ & $<1$ & & 9,89 & 22 & 7,26 & 2 & 19,5 & 208,9 & & 1,1 \\
\hline 03171-PT & 215,94 & $=7$ & 4,05 & $<0,25$ & 1, & $<1$ & $<1$ & $<0,0$ & 1 & $<0,05$ & 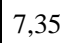 & 3 & 32,7 & 216,9 & 26,4 & 0,8 \\
\hline 03174-PT & 11,06 & 72,4 & 1,86 & $<0,25$ & $<0,5$ & $<1$ & $<1$ & 0,02 & 9,54 & 0,20 & \begin{tabular}{|l|}
7,37 \\
\end{tabular} & 358 & 332,7 & 217,3 & 23,7 & 2,2 \\
\hline 03196-PT & 9,8 & 0 & 2,08 & 0,25 & - & $<1$ & 4,10 & & 10,70 & 0,23 & & 330 & 408,9 & ,2 & & 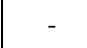 \\
\hline 03206-PT & 19,60 & 9,6 & 2,82 &, 53 & 1,13 & 1,48 & 11,20 & $<0,01$ & 8,50 & ,20 & 6,96 & 291 & 367,1 & 241,1 & 25,0 & 3,6 \\
\hline 03233-2009 & 0,32 & 53,2 & 3,92 & 5 & 0,72 & $<1$ & & $<0,01$ & 12,1 & 5 & & & renc & 9 & & - \\
\hline 03246-PT & 6,76 & 80 & 98 & 0,31 & $<0$ &, 24 & 380 & 0 & 8,2 & $<0,05$ & 6 & 3 & 44,2 & 135,4 & 23,8 & - \\
\hline 04493 & 8,70 &, 0 & 29 & 1,22 & 8,04 & 6,44 & 3,73 & & 3 & 0,19 & & 2) & 04,4 & 132,3 & 24,3 & 15,5 \\
\hline 07 & 204,96 & 58,8 & 5,88 & & & $<1$ & 2,82 & & 23,0 & 55 & 7,19 & & 323,5 &, 5 & 23,9 & 0 \\
\hline 05612-2006 & 5,51 & 30 & 2,22 & 35 & 1,72 & $<1$ & $<1$ & 0 & 6.2 & $<0,05$ & 6 & 432 & 4 & 3,7 & 24,0 & 9,2 \\
\hline 0 & 8, & 81,2 & 1,23 & $<0,25$ & $<0,5$ & $<$ & 2,56 & & 9,37 & & & & 359,4 & 3 & & - \\
\hline 0754 & ,87 & 15,2 & 640 & 1 & 775 & $<1$ & 13 & 0 & 7 & 0 & 6,54 & 308 & 61,5 & 102,2 & 24,4 & 5,4 \\
\hline 079 & 9,64 & 1 & 0,50 & $<1$ & $<0$ & $<$ & $<1$ & 0 & 6,96 & 0,14 & & 462 & 90,5 & 327,6 & 22,7 & ,5 \\
\hline 0869 & 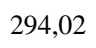 & 117 & 7,12 & 0,37 & $<0,5$ & -1 & 2,38 & 0,02 & 15,3 & 15 & 7,75 & 210 & 2 & 93,0 & 23,2 &, 0 \\
\hline 08767-2011 & 184,22 & 65,8 & 4,78 & & 1,53 & 1,83 & $<$ & 0 , & 10 & $<0,05$ & 7,18 & 2 & 25,8 & 211,0 & 26,5 & 4,0 \\
\hline 0 & 20 & 80,3 & 1,31 & $<0,25$ & 0,72 & $<1$ & 2 , & 0,01 & 10 & 05 & 8 & 496 & 306,2 & 99,3 & 24,5 & 9 \\
\hline 0972 & 217,1 & 81,4 & 0,89 & 0,27 & 1,56 & 1,37 & $<1$ & 0,02 & 9,33 & $<0,05$ & 7 & 179 & 363,3 & 4 & 25,0 & 14,0 \\
\hline 09936-2008 & 152,50 & 44,0 & 2,68 & 0 & 2,79 & $<$ & 3,0 & 0 & 23,60 & 0,24 & 7, & 293 & 33,5 & 150,7 & 23,9 & 3,5 \\
\hline 110 & 2 & 70,7 & 4,40 & 0,53 & 0,55 & $<1$ & $<1$ & 0,01 & 15,3 & 05 & 7 & 362 & 7 & 9 & 24,5 & ,3 \\
\hline 11109-2010 & 247,66 & 73,6 & 3,24 & 0,35 & 2,41 & 3,18 & 2,07 & $<0,01$ & 18,9 & $<0,05$ & 7,04 & 351 & 400,1 & 265,0 & 24,4 & 6,5 \\
\hline
\end{tabular}

*Íons em mg/L

Rosa = Complexo Belo Horizonte, Roxo = Complexo Belo Horizonte + Membro Pedro Leopoldo, Azul claro = Membro Pedro Leopoldo, Azul escuro $=$ Membro Lagoa Santa, Laranja $=$ Membro Lagoa Santa + Fm. Serra de Santa Helena, Verde = Fm. Serra Santa Helena, Amarelo = Colúvio 
Tabela 3 - Continuação.

\begin{tabular}{|c|c|c|c|c|c|c|c|c|c|c|c|c|c|c|c|c|}
\hline \multicolumn{17}{|c|}{ Parâmetros - Análise Poços } \\
\hline & $\mathrm{HCO}_{3}$ & $\mathrm{Ca}^{2+}$ & $\mathbf{M g}^{2+}$ & $\mathbf{K}^{+}$ & $\mathrm{Na}^{+}$ & $\mathrm{Cl}^{-}$ & $\mathrm{SO}_{4}{ }^{2-}$ & $\mathbf{B a}^{2+}$ & $\mathrm{Si}^{4+}$ & $\mathbf{F}^{-}$ & pH & $\begin{array}{c}\mathbf{e H} \\
(\mathrm{mV}) \\
\end{array}$ & $\begin{array}{c}\text { CE } \\
(\mu \mathrm{S} / \mathrm{cm}) \\
\end{array}$ & $\begin{array}{c}\text { STD } \\
(\mathrm{mg} / \mathrm{L}) \\
\end{array}$ & $\mathbf{T}^{\circ} \mathbf{C}$ & $\begin{array}{l}\text { Vazão } \\
\left(\mathrm{m}^{3} / \mathrm{h}\right)\end{array}$ \\
\hline 113-PT & 247,66 & 74,6 & 2,91 & $<0,25$ & 0,63 & $<1$ & 5,51 & 0,04 & 6,16 & 0,29 & 7,49 & 319 & 389,6 & 257,8 & 23,6 & - \\
\hline 12074-2009 & 184,22 & 65,7 & 4,52 & 1,44 & 4,98 & 1,32 & 1,63 & 0,05 & 25,9 & $<0,05$ & 7,38 & 289 & 318,1 & 207,3 & 24,6 & 5,5 \\
\hline 12266-2008 & 101,50 & 26,0 & 4,71 & 0,54 & 2,79 & $<1$ & $<1$ & 0,01 & 23,0 & $<0,05$ & 6,85 & 350 & 163,8 & 103,7 & 25,6 & 3,0 \\
\hline 12268-2008 & 87,96 & 26,3 & 1,56 & $<0,25$ & $<0,5$ & $<1$ & $<1$ & $<0,01$ & 12,30 & $<0,05$ & 7,22 & 391 & 138,1 & 87,3 & 24,5 & 4,6 \\
\hline 12326-2008 & 208,62 & 63,7 & 4,11 & 0,65 & 6,74 & $<1$ & 2,87 & 0,03 & 26,9 & $<0,05$ & 7,78 & 249 & 324,6 & 212,2 & 24,5 & 8,4 \\
\hline 13297-2008 & 240,34 & 65,5 & 1,15 & 0,37 & $<0,5$ & $<1$ & 3,90 & 0,04 & 10,8 & $<0,05$ & 7,28 & 69 & 395,1 & 257,6 & 23,9 & - \\
\hline 14212-2010 & 148,84 & 39,8 & $<0,25$ & $<0,25$ & $<0,5$ & $<1$ & $<1$ & $<0,01$ & 5,12 & 0,12 & 7,55 & 376 & 237,1 & 153,0 & 24,5 & 1,2 \\
\hline 14314-2009 & 254,98 & 75,1 & 4,21 & 0,59 & 6,41 & $<1$ & 3,30 & 0,03 & 21,90 & 0,20 & 7,60 & 406 & 397,8 & 262,1 & 25,6 & 8,8 \\
\hline 15281-2010 & 228,14 & 61,4 & 9,93 & 0,50 & 11,40 & $<1$ & 11,50 & 0,10 & 16,1 & 0,68 & 7,62 & 289 & 364,9 & 237,3 & 26,5 & 0,8 \\
\hline 20198-PT & 253,76 & 77,2 & 3,73 & 0,73 & 3,98 & 7,61 & 9,02 & 0,02 & 10,8 & 0,53 & 7,60 & 765 & 429,8 & 285,2 & 24,2 & 45,0 \\
\hline C-01-ALS & 214,72 & 59,8 & 1,68 & $<0,25$ & $<0,5$ & $<1$ & $<1$ & 0,01 & 18,9 & $<0,05$ & 7,65 & 283 & 336,4 & 219,2 & 24,8 & 90,0 \\
\hline C-01-FPL & 246,44 & 77,9 & 1,96 & 0,26 & 0,78 & $<1$ & 1,82 & 0,04 & 8,85 & 0,13 & 7,34 & 267 & 393,6 & 259,6 & 24,8 & 36,0 \\
\hline C-01-LLS & 223,26 & 59,3 & 5,02 & $<0,25$ & $<0,5$ & $<1$ & 3,61 & 0,02 & 11,5 & $<0,05$ & 7,43 & 307 & 356,7 & 234,3 & 24,5 & 31,3 \\
\hline C-01-SM & 198,86 & 51,5 & 3,26 & 1,35 & 6,32 & 8,25 & 1,85 & 0,05 & 16,5 & $<0,05$ & 7,09 & 147 & 353,0 & 232,7 & 22,7 & 57,6 \\
\hline C-02-CP & 214,72 & 66,9 & 0,53 & $<0,25$ & $<0,5$ & $<1$ & 9,83 & 0,01 & 18,8 & 0,06 & 7,16 & 221 & 386,9 & 255,4 & 31,1 & 20,0 \\
\hline C-03-SC & 197,64 & 54,7 & 1,35 & $<0,25$ & $<0,5$ & $<1$ & $<1$ & $<0,01$ & 9,98 & 0,09 & 7,45 & 309 & 311,9 & 203,8 & 24,9 & 144,0 \\
\hline C-04-SC & 204,96 & 54,5 & 2,40 & $<0,25$ & $<0,5$ & $<1$ & $<1$ & $<0,01$ & 17,5 & $<0,05$ & 7,64 & 245 & 315,1 & 205,5 & 25,2 & 45,0 \\
\hline C-04-SM & 157,38 & 45,7 & 2,92 & 1,01 & 3,48 & 2,87 & 2,55 & 0,01 & 5,64 & $<0,05$ & 7,75 & 239 & 293,6 & 190,7 & - & 240,1 \\
\hline C-08-ALS & 193,98 & 58,6 & 1,78 & 0,27 & 0,98 & 1,47 & 1,33 & 0,02 & 18,6 & $<0,05$ & 7,68 & 287 & 358,7 & 234,6 & - & 72,0 \\
\hline C-09-ALS & 229,36 & 66,1 & 2,36 & 0,62 & 2,31 & 3,97 & 6,98 & 0,02 & 19,3 & 0,13 & 7,47 & 276 & 390,6 & 257,4 & 24,4 & 180,0 \\
\hline C-13-LSL & 190,32 & 55,1 & 1,10 & 0,25 & 0,89 & $<1$ & $<1$ & 0,01 & 8,24 & $<0,05$ & 7,45 & 275 & 310,3 & 201,9 & 24,0 & 72,0 \\
\hline Curral & 247,66 & 98,9 & 1,27 & 1,53 & 0,72 & 3,06 & $<1$ & 0,05 & 10,4 & $<0,05$ & 7,58 & 278 & 393,7 & 259,2 & 25,2 & - \\
\hline E-01-BSM & 200,08 & 53,9 & 2,34 & $<0,25$ & 1,88 & $<1$ & 1,57 & 0,03 & 19,0 & $<0,05$ & 7,28 & 281 & 321,9 & 209,5 & 25,4 & 32,0 \\
\hline E-02-BSM & 186,66 & 52,7 & 1,27 & $<0,25$ & $<0,5$ & $<1$ & $<1$ & $<0,01$ & 18,3 & $<0,05$ & 7,96 & 292 & 301,7 & 196,5 & - & 10,0 \\
\hline HP5 & 214,72 & 76,0 & 2,86 & $<0,25$ & $<0,5$ & $<1$ & 1,06 & 0,01 & 11,9 & $<0,05$ & 7,53 & 310 & 337,1 & 220,9 & 24,6 & 6,8 \\
\hline HP7 & 209,84 & 102,0 & 2,30 & 0,53 & 1,36 & 1,92 & 33,40 & 0,01 & 9,75 & $<0,05$ & 7,29 & 526 & 406,7 & 269,3 & 24,2 & 49,5 \\
\hline N09039 & 206,18 & 42,2 & 1,48 & 0,62 & 63,50 & 2,73 & 25,10 & $<0,01$ & 9,48 & $<0,05$ & 7,77 & 750 & 391,2 & 258,0 & 24,2 & - \\
\hline N12074-2009 & 256,20 & 82,9 & 5,58 & 0,96 & 8,22 & $<1$ & 4,45 & 0,07 & 27,9 & $<0,05$ & 7,27 & 225 & 389,5 & 257,9 & 23,6 & 13,2 \\
\hline N1413 & 117,00 & 31,5 & 2,91 & 0,59 & 4,03 & $<1$ & 6,00 & 0,02 & 29,70 & 0,20 & 7,85 & 300 & 197,0 & 126,5 & 25,5 & - \\
\hline N2340 & 261,08 & 88,8 & 0,86 & 0,56 & 1,81 & 4,12 & 1,79 & 0,05 & 5,99 & 0,49 & 7,26 & 397 & 214,9 & 270,5 & 25,3 & - \\
\hline N26 & 256,20 & 73,3 & 4,26 & 0,28 & 2,09 & $<1$ & 1,24 & 0,02 & 8,59 & $<0,05$ & 7,66 & 292 & 393,5 & 261,1 & 23,4 & - \\
\hline N3 & 131,76 & 24,9 & 6,27 & 0,90 & 12,30 & $<1$ & $<1$ & $<0,01$ & 44,2 & $<0,05$ & 7,39 & 283 & 213,4 & 135,2 & 26,4 & - \\
\hline N30 & 215,94 & 72,1 & 2,14 & 0,60 & 1,43 & $<1$ & 1,45 & 0,03 & 12,00 & 0,22 & 7,63 & 296 & 341,2 & 223,4 & 24,5 & 10,6 \\
\hline N3031 & 94,55 & 27,1 & 1,67 & 0,98 & 2,26 & $<1$ & $<1$ & $<0,01$ & 17,60 & 0,19 & 6,95 & 247 & 107,1 & 745,1 & 24,5 & - \\
\hline N32 & 211,06 & 70,5 & 1,54 & $<0,25$ & 1,14 & $<1$ & $<1$ & 0,02 & 10,5 & 0,21 & 7,98 & 284 & 347,0 & 232,9 & 24,5 & 17,5 \\
\hline N3233 & 201,30 & 56,8 & 2,64 & 0,45 & 2,32 & $<1$ & 1,77 & 0,04 & 18,90 & 0,21 & 7,96 & 279 & 307,7 & 200,5 & 24,1 & 17,5 \\
\hline N33 & 192,76 & 56,5 & 4,14 & 0,68 & 4,11 & $<1$ & 5,39 & 0,08 & 25,40 & 0,25 & 7,77 & 290 & 314,0 & 203,0 & 25,9 & 4,5 \\
\hline N3490 & 286,70 & 97,9 & 4,65 & 1,07 & 12,30 & 9,15 & 4,82 & 0,03 & 16,60 & $<0,05$ & 7,37 & 331 & 506,7 & 337,2 & 25,5 & 180,0 \\
\hline $\begin{array}{l}\text { N35-COP } \\
\text { (C-02-VF) }\end{array}$ & 140,30 & 40,6 & 2,04 & 0,49 & 3,36 & $<1$ & 1,43 & $<0,01$ & 28,80 & 0,20 & 7,80 & 358 & 229,5 & 147,7 & 26,1 & - \\
\hline $\begin{array}{l}\text { N36-COP } \\
\text { (C-04-PF) }\end{array}$ & 179,34 & 45,2 & 3,12 & 0,54 & 13,40 & $<1$ & 2,89 & 0,07 & 28,00 & 0,34 & 7,82 & 634 & 286,8 & 184,6 & 26,6 & 25,2 \\
\hline N52 & 192,76 & 66,1 & 0,38 & $<0,25$ & $<0,5$ & $<1$ & $<1$ & 0,02 & 10,2 & 0,22 & 7,97 & 360 & 298,0 & 194,5 & 21,5 & - \\
\hline N53 & 151,28 & 62,8 & $<0,25$ & $<0,25$ & $<0,5$ & $<1$ & $<1$ & 0,02 & 7,59 & $<0,05$ & 7,72 & 231 & 241,8 & 155,3 & 26,8 & - \\
\hline N8767 & 195,20 & 53,9 & 3,43 & 0,36 & 1,17 & $<1$ & $<1$ & 0,02 & 15,5 & $<0,05$ & 7,33 & 396 & 314,4 & 204,8 & 24,4 & 18,0 \\
\hline Mínimo & 8.54 & 0.3 & 0.13 & 0.13 & 0.25 & 0.50 & 0.50 & 0.005 & 5.12 & 0.03 & 5.08 & 69 & 38.8 & 24.7 & 21,5 & 0.3 \\
\hline Máximo & 436.76 & 169 & 9.93 & 3.89 & 63.50 & 18.7 & 33.40 & 0.1 & 75,00 & 0.68 & 8.12 & 771 & 644.2 & 435.4 & 29,0 & 240.1 \\
\hline Média & 199.54 & 62,9 & 2.86 & 0.49 & 3.48 & 1.53 & 2.79 & 0.03 & 16.63 & 0.11 & 7.34 & 323 & 320.9 & 210.5 & 24.7 & 30.0 \\
\hline $\begin{array}{l}\text { Desvio } \\
\text { Padrão }\end{array}$ & 69.55 & 28.8 & 2.07 & 0.55 & 7.50 & 2.64 & 4.85 & 0.02 & 12,00 & 0.13 & 0.50 & 120 & 102.6 & 69.2 & 1.2 & 52.5 \\
\hline Mediana & 208.62 & 63.7 & 2.36 & 0.29 & 1.17 & 0.50 & 1.32 & 0.02 & 12.10 & 0.03 & 7.43 & 300 & 332.7 & 217.3 & 24.5 & 8.8 \\
\hline
\end{tabular}




\begin{tabular}{|c|c|c|c|c|c|c|c|c|c|c|c|c|c|c|c|c|}
\hline & $\mathrm{Ca}^{2+}$ & $\mathbf{M g}^{2+}$ & $\mathbf{K}^{+}$ & $\mathrm{Na}^{+}$ & $\mathrm{HCO}_{3}{ }^{-}$ & $\mathrm{Cl}^{-}$ & $\mathrm{SO}_{4}{ }^{2-}$ & $\mathrm{Ba}^{2+}$ & $\mathrm{Si}^{4+}$ & $\mathbf{F}^{-}$ & pH & STD & $\underset{\mathrm{CaCO}_{3}}{\mathrm{IS}}$ & $\begin{array}{c}\mathrm{IS} \\
\mathrm{CaMgCO}_{3}\end{array}$ & \begin{tabular}{|c|} 
Cota \\
Média \\
Entrada \\
D'água \\
\end{tabular} & Vazão \\
\hline $\mathrm{Ca}^{2+}$ & 1,00 & $-0,22$ & 0,10 & $-0,21$ & 0,89 & 0,17 & 0,23 & 0,49 & $-0,36$ & 0,21 & 0,07 & 0,89 & 0,57 & 0,32 & 0,03 & $-0,02$ \\
\hline $\mathbf{M g}^{2+}$ & $-0,22$ & 1,00 & 0,42 & 0,59 & $-0,08$ & 0,09 & 0,35 & $-0,12$ & 0,61 & $-0,26$ & $-0,12$ & $-0,04$ & $-0,17$ & 0,27 & $-0,30$ & 0,17 \\
\hline $\mathbf{K}^{+}$ & 0,10 & 0,42 & 1,00 & 0,69 & 0,09 & 0,48 & 0,54 & 0,36 & 0,34 & $-0,09$ & $-0,16$ & 0,24 & $-0,09$ & 0,06 & $-0,12$ & 0,05 \\
\hline $\mathrm{Na}^{+}$ & $-0,21$ & 0,59 & 0,69 & 1,00 & $-0,12$ & 0,44 & 0,45 & 0,12 & 0,43 & $-0,08$ & $-0,17$ & 0,00 & 0,01 & 0,10 & $-0,22$ & 0,25 \\
\hline $\mathrm{HCO}_{3}^{-}$ & 0,89 & $-0,08$ & 0,09 & $-0,12$ & 1,00 & 0,08 & 0,37 & 0,49 & $-0,21$ & 0,20 & 0,18 & 0,93 & 0,66 & 0,51 & $-0,05$ & 0,12 \\
\hline $\mathrm{Cl}^{-}$ & 0,17 & 0,09 & 0,48 & 0,44 & 0,08 & 1,00 & 0,28 & 0,05 & $-0,12$ & $-0,14$ & $-0,28$ & 0,31 & $-0,08$ & $-0,02$ & 0,30 & 0,24 \\
\hline $\mathrm{SO}_{4}{ }^{2-}$ & 0,23 & 0,35 & 0,54 & 0,45 & 0,37 & 0,28 & 1,00 & 0,32 & 0,13 & 0,23 & $-0,03$ & 0,46 & 0,05 & 0,12 & $-0,07$ & 0,10 \\
\hline $\mathbf{B a}^{2+}$ & 0,49 & $-0,12$ & 0,36 & 0,12 & 0,49 & 0,05 & 0,32 & 1,00 & $-0,06$ & 0,22 & $-0,11$ & 0,53 & 0,18 & 0,09 & $-0,15$ & $-0,12$ \\
\hline $\mathrm{Si}^{4+}$ & $-0,36$ & 0,61 & 0,34 & 0,43 & $-0,21$ & $-0,12$ & 0,13 & $-0,06$ & 1,00 & $-0,23$ & 0,01 & $-0,23$ & $-0,15$ & 0,16 & $-0,59$ & $-0,08$ \\
\hline $\mathbf{F}^{-}$ & 0,21 & $-0,26$ & $-0,09$ & $-0,08$ & 0,20 & $-0,14$ & 0,23 & 0,22 & $-0,23$ & 1,00 & 0,16 & 0,19 & 0,16 & 0,11 & 0,18 & $-0,07$ \\
\hline pH & 0,07 & $-0,12$ & $-0,16$ & $-0,17$ & 0,18 & $-0,28$ & $-0,03$ & $-0,11$ & 0,01 & 0,16 & 1,00 & 0,10 & 0,83 & 0,80 & $-0,07$ & 0,11 \\
\hline STD & 0,89 & $-0,04$ & 0,24 & 0,00 & 0,93 & 0,31 & 0,46 & 0,53 & $-0,23$ & 0,19 & 0,10 & 1,00 & 0,60 & 0,47 & 0,07 & 0,26 \\
\hline IS $\mathrm{CaCO}_{3}$ & 0,57 & $-0,17$ & $-0,09$ & 0,01 & 0,66 & $-0,08$ & 0,05 & 0,18 & $-0,15$ & 0,16 & 0,83 & 0,60 & 1,00 & 0,87 & $-0,03$ & 0,11 \\
\hline $\begin{array}{c}\text { IS } \\
\mathrm{CaMgCO}_{3}\end{array}$ & 0,32 & 0,27 & 0,06 & 0,10 & 0,51 & $-0,02$ & 0,12 & 0,09 & 0,16 & 0,11 & 0,80 & 0,47 & 0,87 & 1,00 & $-0,16$ & 0,19 \\
\hline $\begin{array}{c}\text { Cota } \\
\text { Média } \\
\text { Entrada } \\
\text { D'água }\end{array}$ & 0,03 & $-0,30$ & $-0,12$ & $-0,22$ & $-0,05$ & 0,30 & $-0,07$ & $-0,15$ & $-0,59$ & 0,18 & $-0,07$ & 0,07 & $-0,03$ & $-0,16$ & 1,00 & 0,22 \\
\hline Vazão & $-0,02$ & 0,17 & 0,05 & 0,25 & 0,12 & 0,24 & 0,10 & $-0,12$ & $-0,08$ & $-0,07$ & 0,11 & 0,26 & 0,11 & 0,19 & 0,22 & 1,00 \\
\hline
\end{tabular}

Figura 9 - Matriz correlação das águas de poços associadas aos calcários dos Membros Pedro Leopoldo e Lagoa Santa.

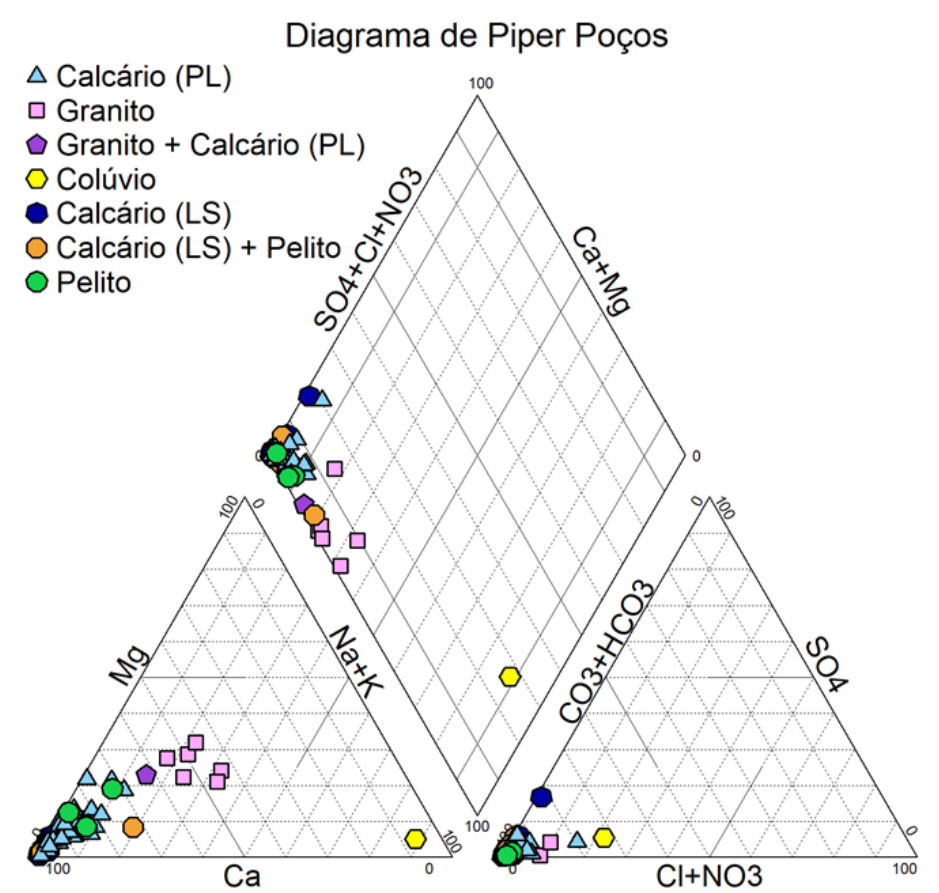

Figura 10 - Diagrama de Piper para as águas de poços na área do projeto (Vieira, 2018).

profundas, principalmente em relação às concentrações de $\mathrm{Ca}^{2+}, \mathrm{Mg}^{2+}, \mathrm{Na}^{+}$e $\mathrm{Si}^{4+}$, assim também como a sua diferenciação das águas do Membro Lagoa Santa (Figura 11).

As águas de circulação profunda associadas ao Membro Pedro Leopoldo podem ser subdivididas em quatro diferentes tipos hidroquímicos, correlatos à classificação das rochas da figura 3, a partir da distribuição espacial de $\mathrm{Ca}^{2+}, \mathrm{Si}^{4+}$ e, subordinadamente, $\mathrm{Mg}^{2+}$ (Figura 12): (i) altas concentrações de $\mathrm{Ca}^{2+}$, baixas de $\mathrm{Si}^{4+}$ e intermediárias de $\mathrm{Mg}^{2+}$, de ocorrência bastante dispersa na área, apontando para uma forte descontinuidade dessa fácies litológica, correspondente aos calcários mais ou menos magnesianos, similar às águas que circulam nas rochas puras do Membro Lagoa 
Santa; (ii) altas concentrações de $\mathrm{Ca}^{2+}$ e $\mathrm{Mg}^{2+}$, e intermediárias de $\mathrm{Si}^{4+}$, principalmente em faixas de direção NW-SE e NE-SW ao sul e sudeste, próximo de Vespasiano, que correspondem a calcários dolomíticos-silicosos; (iii) baixas concentrações de $\mathrm{Ca}^{2+}$, elevadas de $\mathrm{Si}^{4+}$ e intermediárias de $\mathrm{Mg}^{2+}$, distribuído especialmente por toda borda leste, correspondendo, portanto, aos cherts calcários silicosos; e (iv) intermediárias a baixas concentrações de $\mathrm{Ca}^{2+}$, baixas de $\mathrm{Si}^{4+}$ e intermediárias de $\mathrm{Mg}^{2+}$, localizado principalmente na porção sudeste (região da bacia do Jaque), correlato à fácies dos calcários silicosos mais ou menos magnesianos.
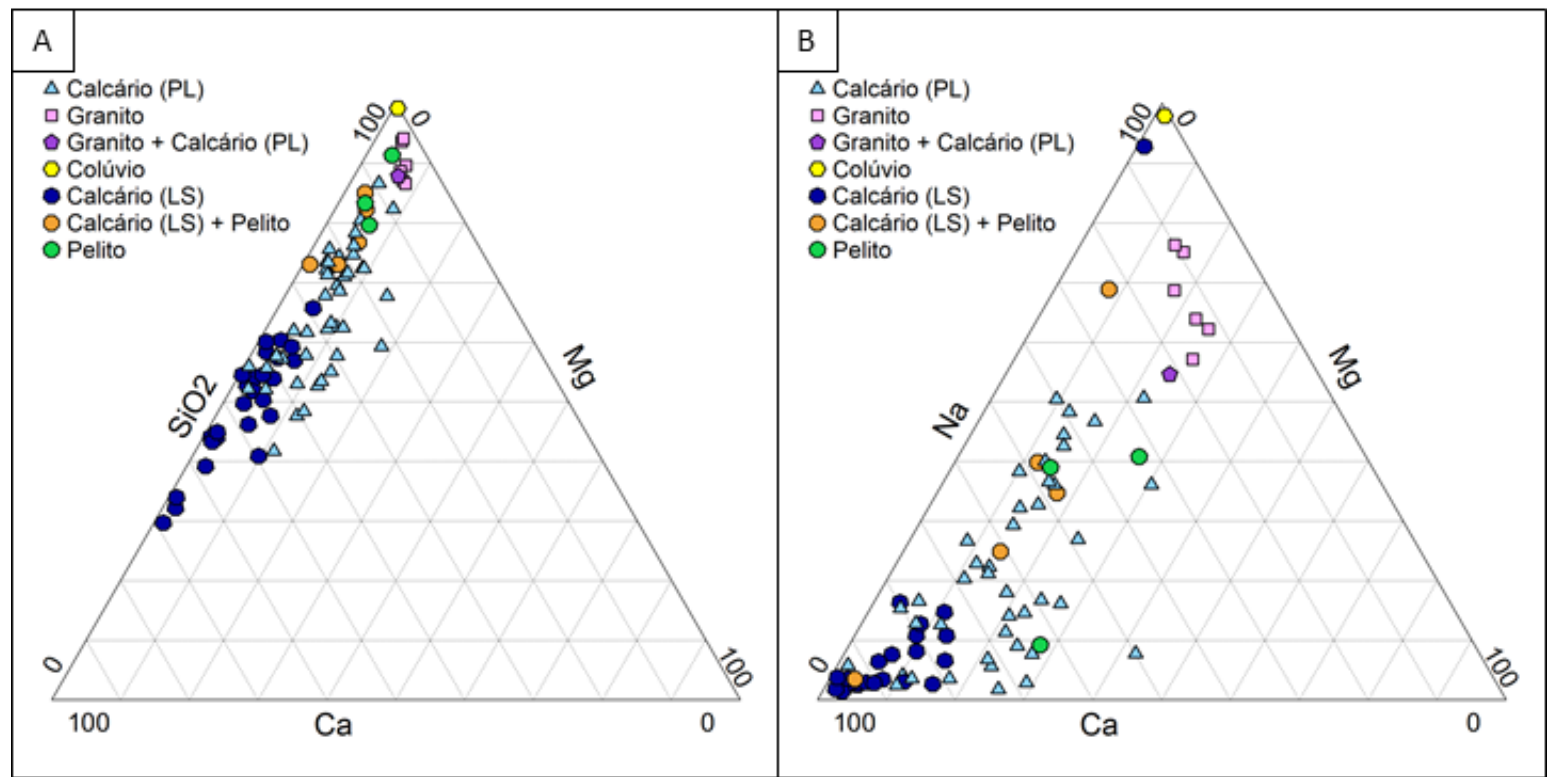

Figura 11 - Diagramas ternários para águas de poços da área de estudo, separados pela classificação hidrogeológica: A) Ca-Mg-SiO 2 e B) Ca-Mg-Na. Utilizou-se um fator de multiplicação de 5 para as concentrações de $\mathrm{Mg}^{2+}$ e de 10 para as de $\mathrm{Si}^{4+}$ e $\mathrm{Na}^{+}$, para auxiliar a visualização e interpretação dos dados (Vieira, 2018).
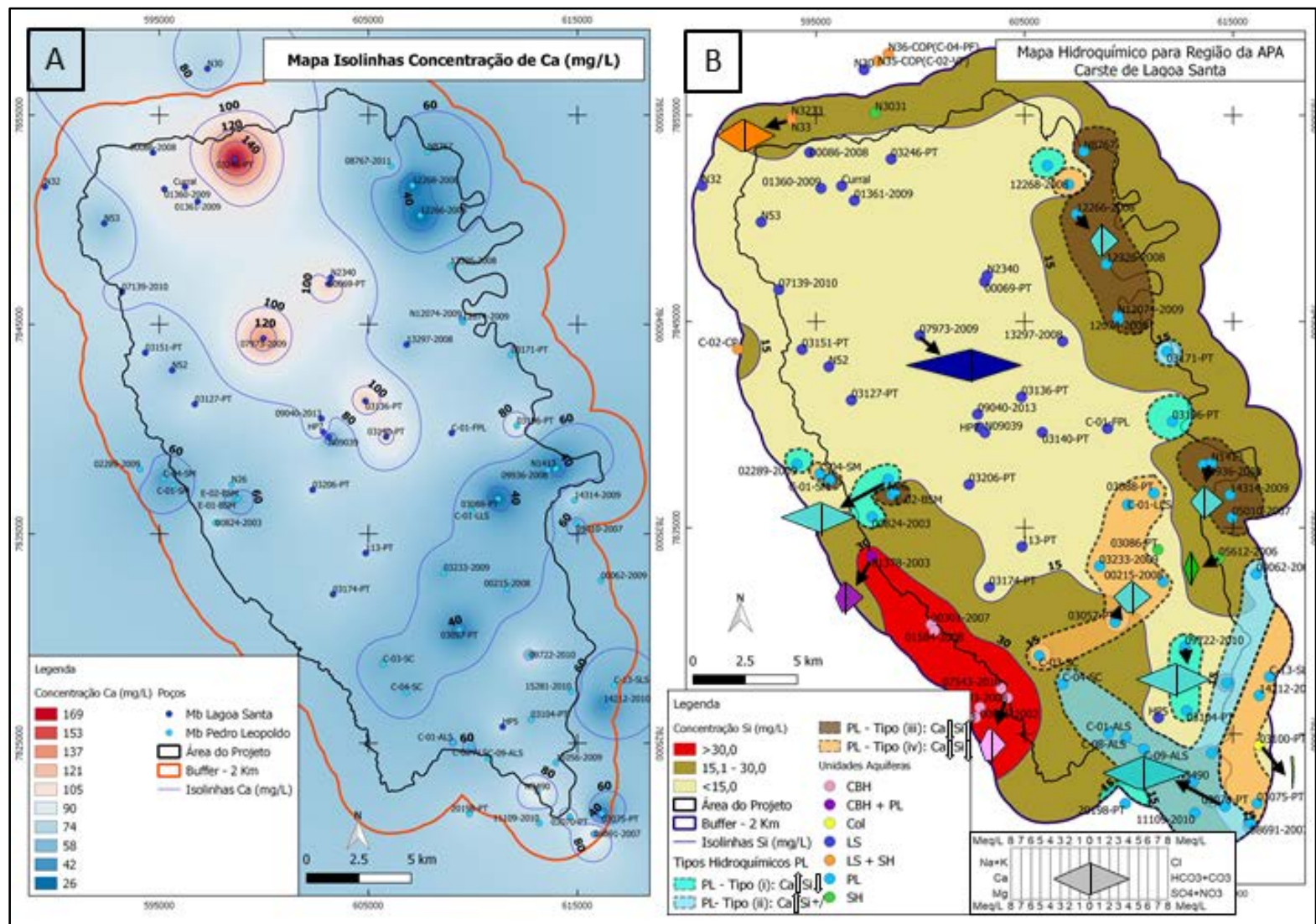

Figura 12 - Mapas das águas de poços profundos para: A) Concentração, em mg/L, de $\mathrm{Ca}^{2+}$ dos Membros Pedro Leopoldo e Lagoa Santa; e B) Mapa hidroquímico a partir da concentração de $\mathrm{Si}^{4+}$, mostrando a composição representativa de Stiff nas unidades aquíferas. Sobre o Membro Pedro Leopoldo foram representados os quatro tipos hídricos determinados a partir dos mapas de isolinhas e concentrações de $\mathrm{Ca}^{2+}$ e $\mathrm{Si}^{4+}$ (Vieira, 2018). 
A compartimentação horizontal é marcada pelo aumento da concentração de $\mathrm{Si}^{4+}$ para leste, concomitantemente à maior frequência de intercalações pelíticas dos calcários do Membro Pedro Leopoldo. É propiciada, portanto, muito mais pelas mudanças litológicas dos aquíferos do que pela evolução química.

As variações hidroquímicas verticais são controladas principalmente pelas concentrações de $\mathrm{Si}^{4+}$, exibindo valores mais altos à medida que se atinge cotas de entradas d'água menores $(\mathrm{R}=$ 0,59). Esta distribuição retrata a posição estratigráfica das rochas, com maior teor de $\mathrm{SiO}_{2}$ na base, o Complexo Belo Horizonte e os calcários impuros do Membro Pedro Leopoldo sobrepostos pelos calcários essencialmente calcíticos do Membro Lagoa Santa.

A produtividade dos poços está intimamente ligada à composição química das rochas, cuja pureza composicional propicia a ocorrência de processos de dissolução e a consequente carstificação, permitindo maior fluxo subterrâneo, como visto claramente nas águas subsuperficiais por meio das nascentes do Membro Lagoa Santa. O controle da litoquímica pode ser observado tanto nas capacidades específicas dos poços associados ao Membro Lagoa Santa quanto na ocorrência de maior produtividade em águas do Membro Pedro Leopoldo do tipo (ii), caracterizadas pelas altas concentrações de $\mathrm{Ca}^{2+}$ e intermediárias de $\mathrm{Si}^{4+}$, ao contrário daquelas dos tipos (iii) e (iv), com baixos valores de $\mathrm{Ca}^{2+}$ (Figura 13A).

Obteve-se uma mediana de capacidade específica de $1,50 \mathrm{~m}^{3} / \mathrm{h} / \mathrm{m}$ para os do Membro Pedro Leopoldo e $1,15 \mathrm{~m}^{3} / \mathrm{h} / \mathrm{m}$ para os do Membro Lagoa Santa. O maior valor para o primeiro membro é contrário ao esperado, entretanto, esse resultado pode estar sendo influenciado por dois fatores: condições estruturais locais de cavalgamento das camadas presentes na porção sul, onde os poços no Membro Pedro Leopoldo são os mais produtivos de toda a área (Figura 13A), com cotas médias de entradas d’águas intermediárias (600-650m); possibilidade de que esses poços concentrados a sul estejam captando também, por conexão através de fraturas ou dutos, as águas do Ribeirão da Mata. Assim, os resultados indicaram um controle estrutural importante na produtividade dos poços associados aos calcários mais calcíticos do Membro Pedro Leopoldo, como os

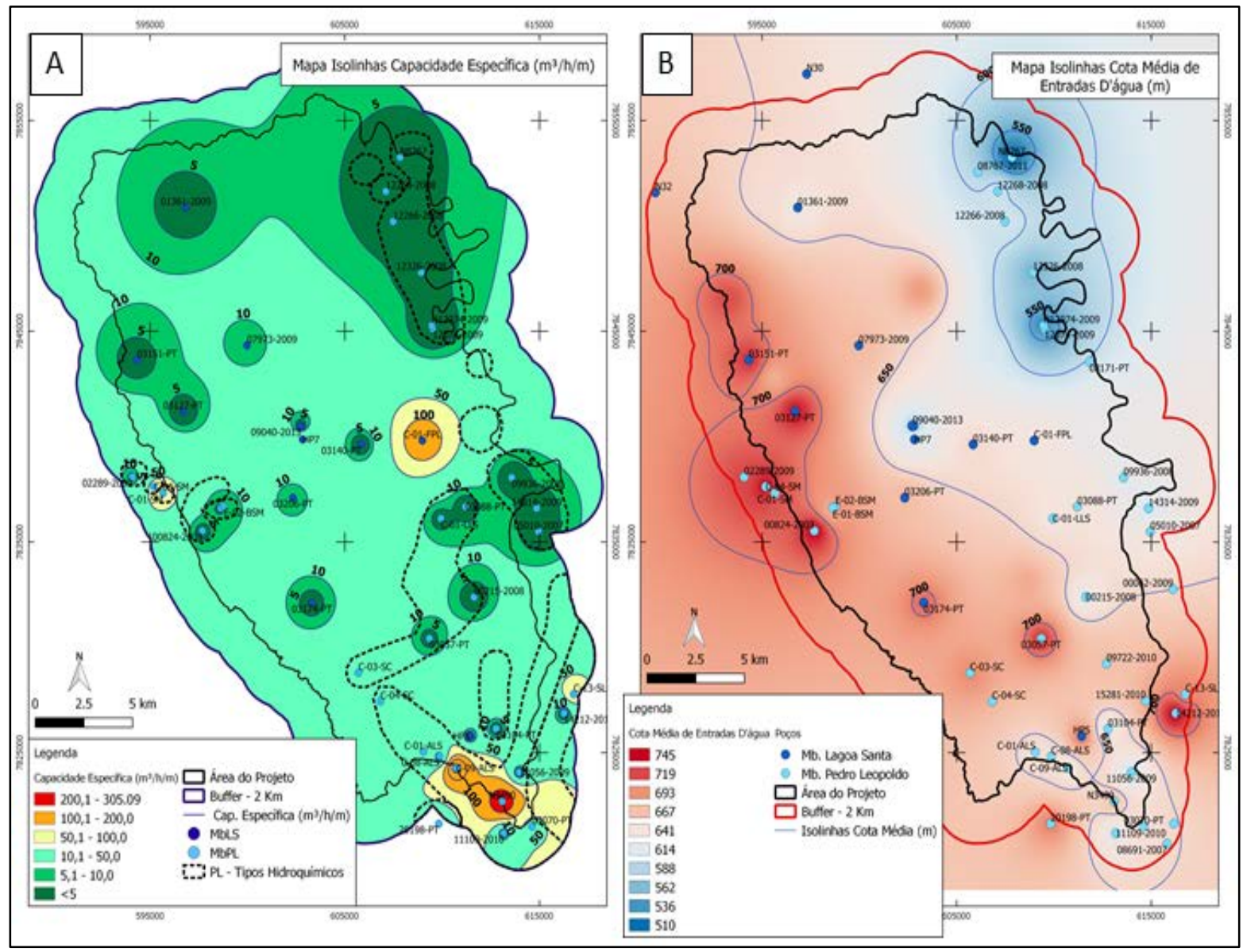

Figura 13 - Mapas das águas de poços tubulares associadas aos calcários dos Membros Pedro Leopoldo e Lagoa Santa para: A) Cotas médias de entradas d’água, em m; e B) Capacidade específica (m³/h/m) (Vieira, 2018). 
que se encontram alinhados segundo direção NW-SE e próximos a zona de contato entre os membros. Nas proximidades destes poços foram observadas falhas de empurrão com dobras de arraste, que indicam a ocorrência de falhamentos importantes e rochas do Membro Pedro Leopoldo imediatamente sotoposto pelos pelitos da Fm. Serra de Santa Helena (Vieira, 2015; Ribeiro et al., 2016).

As profundidades próximas ao contato entre os dois membros se mostra uma importante superfície preferencial de percolação de água, uma vez que as maiores vazões do Membro Lagoa Santa ocorrem em cotas médias de entradas d'água mais baixas (Figura 13B), juntamente com o aumento da concentração de $\mathrm{Na}^{+}$e $\mathrm{K}^{+} \quad(\mathrm{R}=-0,51$ e $\mathrm{R}=-0,42)$, íons que aumentam a solubilidade de $\mathrm{CaCO}_{3}$ (Santos, 2008) e que estão predominantemente presentes nas águas do Membro Pedro Leopoldo.

\section{CONCLUSÕES}

A geologia, tanto no âmbito da litoquímica quanto da estrutural, possui papel fundamental na composição química das águas subterrâneas de circulação rasa e profunda, possibilitando a identificação e distinção entre as mesmas em unidades aquíferas, especialmente as águas provenientes dos granitos do Complexo Belo Horizonte, laterita da Cobertura DetritoLaterítica e dos pelitos da Formação Serra de Santa Helena.

Nas águas representativas dos calcários, as intercalações pelíticas do Membro Pedro Leopoldo são primordiais para a distinção entre esta unidade e o Membro Lagoa Santa, embora a diferenciação seja dificultada pela subdivisão das águas do primeiro membro em quatro tipos hidroquímicos segundo concentrações de $\mathrm{Ca}^{2+} \mathrm{e}$ $\mathrm{Si}^{4+}$.

As compartimentações horizontal e vertical são marcadas pelo aumento da concentração de $\mathrm{Si}^{4+}$ no sentido NW-SE, estendendo também para toda porção leste e com a profundidade. Do ponto de vista geológico, essa disposição segue dos calcários essencialmente calcíticos do Membro Lagoa Santa em direção às rochas impuras do Membro Pedro Leopoldo, que aumentam seu teor de dolomita, micas e clorita a leste. O aumento da concentração de $\mathrm{Si}^{4+}$ e da vazão em profundidade nas águas de circulação profunda do Membro Lagoa Santa é explicada pela aproximação ao seu contato litológico, ora gradacional, ora tectônico, com o membro inferior, que atua, ainda, como superfície preferencial de percolação da água.

A produtividade dos poços, inclusive, mostrase fortemente controlada pela união dos fatores estruturais, como zonas de contato e falhas, especialmente a de direção NW-SE ao sul da área, e da pureza composicional das rochas que aumentam a susceptibilidade a processos de dissolução. A combinação destes fatores explica a ocorrência isolada de alta produtividade nos poços do Membro Pedro Leopoldo comparados com os do Membro Lagoa Santa.

A circulação rasa das águas, por sua vez, é especialmente controlada pela litoquímica, uma vez que mesmo com fraturamento em ambos os membros, a unidade superior (Membro Lagoa Santa), de composição essencialmente calcítica, apresenta-se intensamente mais carstificada e com vazões consideravelmente mais elevadas nas surgências e ressurgências.

\section{AGRADECIMENTOS}

Agradecimento ao CECAV/ICMBio pelo apoio financeiro ao "Projeto de Adequação e Implantação de uma Rede de Monitoramento de Águas Subterrâneas em Áreas com Cavidades Cársticas da Bacia do Rio São Francisco Aplicado à Área Piloto da APA Carste de Lagoa Santa, Minas Gerais” parceria entre UFMG e CDTN, e com apoio do IGAM, e CPRM - Serviço Geológico do Brasil.

\section{REFERÊNCIAS}

ALKMIM, F.F. O que faz de um cráton um cráton? O Cráton do São Francisco e as revelações almeidianas ao delimitá-lo. In: V. MANTESSO-NET; A. BARTORELLI; C.D.R. CARNEIRO; B.B. BRITO NEVES (orgs.) Geologia do Continente SulAmericano: evolução da obra de Fernando Flávio Marques de Almeida. São Paulo: Beca, p. 17-35, 2004.

ALKMIM F.F. \& MARTINS-NETO M.A. A bacia intracratônica do São Francisco: arcabouço estrutural e cenários evolutivos. In: C.P. Pinto \& M.A. Martins-Neto (eds.). A Bacia do São Francisco geologia e recursos naturais. Sociedade Brasileira de Geologia: Belo Horizonte, p. 9-30, 2001.

ALMEIDA, F.F.M. O Cráton do São Francisco. Revista Brasileira Geociências, v.7, p.349-364, 1977.

AULER, A. Hydrogeological and Hydrochemical Characterization of the Matozinhos-Pedro Leopoldo Karst, Brazil. Kentucky (US), 1994. 110 p. Tese (Doutorado) Western Kentucky University.

BATISTA, R.C.B. Caracterização hidrogeológica do entorno do Centro Nacional de Pesquisa Milho e Sorgo (CNPMS) em Sete Lagoas - MG. Belo Horizonte, 2009. 127 p. 
Dissertação (Mestrado em Engenharia Sanitária), Programa de Pós-Graduação em Saneamento - Meio Ambiente e Recursos Hídricos, Universidade Federal de Minas Gerais.

BATISTA, T.S.A. \& SANTOS FILHO, J.B. DOS. Calcita, Hidroxiapatita e B-Fosfato Tricálcio como absorvedores do ultravioleta. 1 ed. Aracaju: IFS, 190 p, 2016.

CARNEIRO, F.A. Modelagem hidrogeoquímica do sistema aquífero pelito-carbonático existente no CNPMS da Embrapa Sete Lagoas, MG, Brasil. Belo Horizonte, 2013. 338 p. Tese (Doutorado em Engenharia Sanitária), Programa de Pós-Graduação em Saneamento - Meio Ambiente e Recursos Hídricos, Universidade Federal de Minas Gerais.

CPRM - COMPANHIA DE PESQUISA DE RECURSOS MINERAIS - SERVIÇO GEOLÓGICO DO BRASIL. Informações Básicas para a Gestão Territorial - Região de Sete Lagoas e Lagoa Santa, Minas Gerais. Belo Horizonte: Convênio Secretaria de Minas e Metalurgia / Companhia de Pesquisa de Recursos Minerais - Serviço Geológico do Brasil, 84 p. 1994.

CPRM - COMPANHIA DE PESQUISA DE RECURSOS MINERAIS - SERVIÇO GEOLÓGICO DO BRASIL; IBAMA - INSTITUTO BRASILEIRO DO MEIO AMBIENTE E DOS RECURSOS NATURAIS RENOVÁVEIS. Série APA Carste de Lagoa Santa - Meio Físico. Belo Horizonte: Convênio Instituto Brasileiro do Meio Ambiente e dos Recursos Naturais Renováveis / Companhia de Pesquisa de Recursos Minerais Serviço Geológico do Brasil, 300 p. 1998.

CPRM - COMPANHIA DE PESQUISA DE RECURSOS MINERAIS - SERVIÇO GEOLÓGICO DO BRASIL. Projeto Vida: Mapeamento Geológico - Região de Sete Lagoas, Pedro Leopoldo, Matozinhos, Lagoa Santa, Vespasiano, Capim Branco, Prudente de Moraes, Confins e Funilândia - Minas Gerais - Relatório Final. Belo Horizonte: Convênio Secretária de Minas e Energia / Companhia de Pesquisa de Recursos Minerais - Serviço Geológico do Brasil, 54 p., 2003.

CPRM - COMPANHIA DE PESQUISA DE RECURSOS MINERAIS - SERVIÇO GEOLÓGICO DO BRASIL. Projeto Sete Lagoas - Abaeté. Belo Horizonte: Convênio Secretária de Geologia, Mineração e Transformação Mineral/Companhia de Pesquisa de Recursos Minerais - Serviço Geológico do Brasil, 160 p., 2010.

DARDENNE, M.A. Síntese Sobre a Estratigrafia do Grupo Bambuí no Brasil Central. In: CONGRESSO BRASILEIRO DE GEOLOGIA, 30, 1978, Recife. Anais.... Recife: Sociedade Brasileira Geologia, n. 2, p.5 97-610, 1978.

GALVÃO, P.H.F. Modelo hidrogeológico conceitual de Sete Lagoas (MG) e implicações associadas ao desenvolvimento urbano em regiões cársticas. São Paulo, 2015. 124 p. Tese (Doutorado), Universidade de São Paulo.

LIMA, E.S.A.; SOBRINHO, N.M.B.A.; MAGALHÃES, M.O.L.; GUEDES, J.N.; ZONTA, E. Absorção de bário por plantas de arroz (Oryza sativa L.) e mobilidade em solo tratado com baritina sob diferentes condições de potencial redox. Quim. Nova, v. 35, n. 9, p. 1746-1751, 2012.

MACHADO, D.A. Caracterização hidrogeológica e vulnerabilidade natural das águas subterrâneas no entorno do Centro Nacional de Pesquisa Milho e Sorgo - Sete Lagoas/MG. Belo Horizonte, 2011. 230 p. Dissertação (Mestrado em Saneamento, Meio Ambiente e Recursos Hídricos), Programa de Pós-Graduação em Saneamento, Meio Ambiente e Recursos Hídricos, Universidade Federal de Minas Gerais.

MESTRINHO, S.S.P. Geoquímica das Águas Subterrâneas. In: FEITOSA, F.A.C.; FILHO, J.M.; FEITOSA, E.C.; DEMETRIO, J.G. Hidrogeologia Conceitos e Aplicações. 3 ed. Rio de Janeiro: CPRM: LABHID, p. 359- 379, 2008.

MICHE, H.; SIMLER, R.; AFFATON, P.; MICKALA, O.; BOUDZOUMOU, F.; MBINA, M. New Computerized Method for the Geochemical Classification of Precambrian Carbonate Rocks : Case of a Set of African Cap Carbonates. International Journal of Geosciences, v. 4, n. 0, p. 37-49, 2013.

MICROSOFT OFFICE PROFESSIONAL PLUS. Microsoft Excel. Versão 1.5. [S.l.]: Microsoft Corporation, 2013. 1 CDROM

PESSOA, P.F.P. Hidrogeologia dos aquíferos cársticos da região de Lagoa Santa, MG. Belo Horizonte, 2005. 375 p. Tese (Doutorado em Meio Ambiente, Escola de Engenharia, Universidade Federal de Minas Gerais.

QGIS Development Team. QGIS Geographic Information System. Open Source Geospatial Foundation Project, version 2.8.9 - Wien. http://www.qgis.org/

RIBEIRO, C.G.; MEIRELES C.G.; LOPES N.H.B.; ARCOS R.E.C. Levantamento Geológico Estrutural Aplicado aos Fluxos dos Aquíferos Cárstico-Fissurais da Região da APA Carste de Lagoa Santa, Minas Gerais. Belo Horizonte, 2016. 122 p. Trabalho Geológico de Graduação, Instituto de Geociências - Universidade Federal de Minas Gerais.

RIBEIRO, C.G.; VELASQUEZ, L,N,M.; MEIRELES C.G.; PAULA, R.S. Análise dos fluxos nos aquíferos cársticofissurais da região da APA Carste de Lagoa Santa, MG. Águas Subterrâneas, v. 33, n.1, p. 12-21, 2019.

SANTOS, A.C. Noções de hidroquímica. In: FEITOSA, F.A.C.; FILHO, J.M.; FEITOSA, E.C.; DEMETRIO, J.G. Hidrogeologia: conceitos e aplicações. 3 ed. Rio de Janeiro: CPRM: LABHID, p. 323-357, 2008.

SILVA, J.C.S. Caracterização hidrogeológica ambiental da área de influência da Mina Lapa Vermelha, na região cárstica de Lagoa Santa, MG. Belo Horizonte, 2003. 303 p. Dissertação (Mestrado em Saneamento, Meio Ambiente e Recursos Hídricos, Escola de Engenharia - Universidade Federal de Minas Gerais

SILVA, A.B. Hidrogeologia de Meios Cársticos. In: FEITOSA, F.A.C.; FILHO, J.M.; FEITOSA, E.C.; DEMETRIO, J.G. Hidrogeologia: conceitos e aplicações. 3 ed. Rio de Janeiro: CPRM: LABHID, p. 153-174, 2008.

STATSOFT, INC. STATISTICA (data analysis software system), version 10, 2011. Disp. em: www.statsoft.com.

USGS - UNITED STATES GEOLOGICAL SURVEY. Phreeqc Interative. Versão 3.3.12.12704, 2017.

VIEIRA, L.C.M. Características da Geologia e Geoquímica do Grupo Bambuí na APA Carste de Lagoa Santa, MG. Belo Horizonte, 2015. 102 p. Trabalho Geológico de Graduação, Instituto de Geociências - Universidade Federal de Minas Gerais.

VIEIRA, L. C. M. Hidrogeoquímica dos Aquíferos da Região da APA Carste de Lagoa Santa, MG. Belo Horizonte, 2018, 109p. Dissertação (Mestrado em Geologia Econômica e Aplicada) - Programa de Pós-Graduação em Geologia, Universidade Federal de Minas Gerais.

VIEIRA, L.C.M.; DUSSIN, T.M.; VELÁSQUEZ, L.N.M. Geoquímica e Condições Paleoambientais de Deposição das Rochas Carbonáticas da Formação Sete Lagoas na Região da Área de Proteção Ambiental Carste de Lagoa Santa, MG. Geochimica Brasiliensis, v. 2, n. 1, p. 1-19, 2018.

Submetido em 11 de dezembro de 2018 Aceito para publicação em 20 de outubro de 2020 